\title{
A Novel Formal Total Synthesis of Cephalotaxine
}

\author{
Wei-Dong Z. $\mathrm{Li}^{*}{ }^{\dagger, \dagger}$ and Bao-Chun $\mathrm{Ma}^{\dagger}$ \\ †State Key Laboratory of Applied Organic Chemistry, Lanzhou University, Lanzhou 730000, China \\ ${ }^{\dagger}$ State Key Laboratory of Elemento-organic Chemistry, Nankai University, Tianjin 300071, China
}

liwd@1zu.edu.cn; wdli@nankai.edu.cn

\section{Contents}

1. ${ }^{1} \mathrm{H}$ and ${ }^{13} \mathrm{C}$ NMR spectrum of $\mathbf{1 0}$ and its 3,4-dimethoxyl congener ......................S2-S5

2. ${ }^{1}$ H NMR spectrum of $\mathbf{1 1}$ and its 3,4-dimethoxyl congener...................................S6

3. ${ }^{1} \mathrm{H}$ and ${ }^{13} \mathrm{C}$ NMR, and IR spectrum of 9 and its 3,4-dimethoxyl congener ...............S7-S9

4. ${ }^{1} \mathrm{H}$ and ${ }^{13} \mathrm{C}$ NMR, IR and HRMS spectrum of $\mathbf{1 3}$ and its 3,4-dimethoxyl congener......S10-S12

5. ${ }^{1} \mathrm{H}$ and ${ }^{13} \mathrm{C}$ NMR, IR and HRMS spectrum of 14a............................... S13-S14

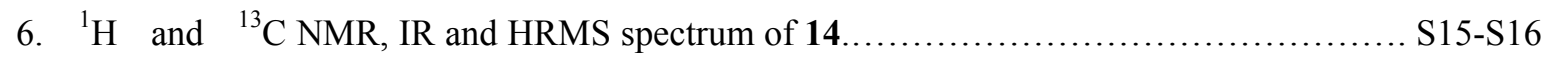

7. ${ }^{1} \mathrm{H}$ and ${ }^{13} \mathrm{C}$ NMR spectrum of $\mathbf{1 5}$ and its 3,4-dimethoxyl congener ................... S17-S19

8. ${ }^{1} \mathrm{H}$ and ${ }^{13} \mathrm{C}$ NMR, and HRMS spectrum of $\mathbf{4}$ and its 3,4-dimethoxyl congener ...........S20-S22

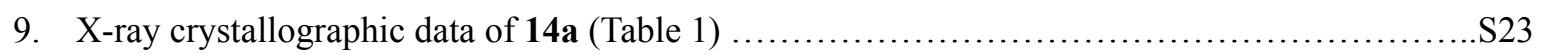


maobch

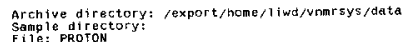

pulse sequence: $52 p u l$

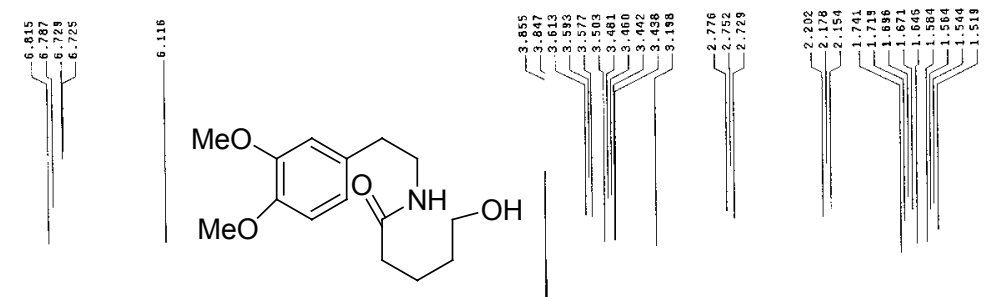

${ }^{1} \mathrm{H} \mathrm{NMR}\left(\mathrm{CDCl}_{3}, 300 \mathrm{MHz}\right)$

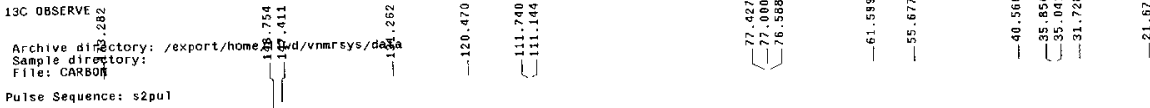

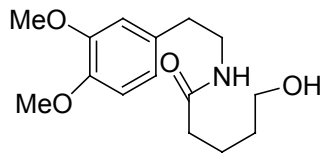

DEPT(135, $\left.\mathrm{CDCl}_{3}, 75 \mathrm{MHz}\right)$
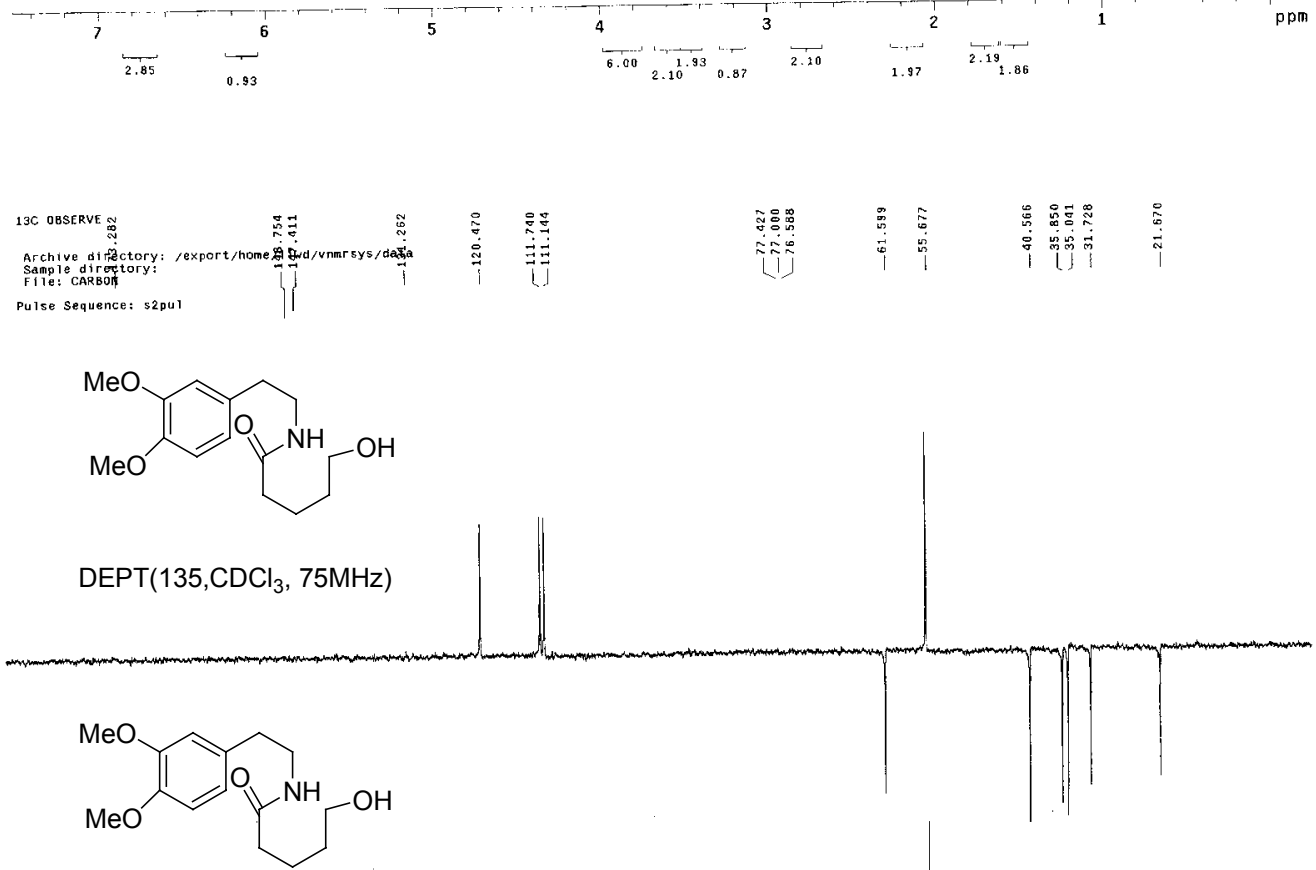

${ }^{3} \mathrm{C}$ NMR $\left(\mathrm{CDCl}_{3}, 75 \mathrm{MHz}\right)$

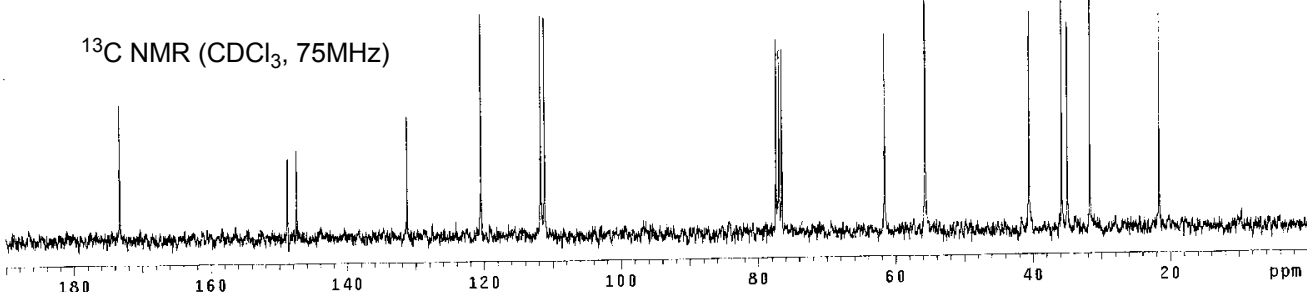



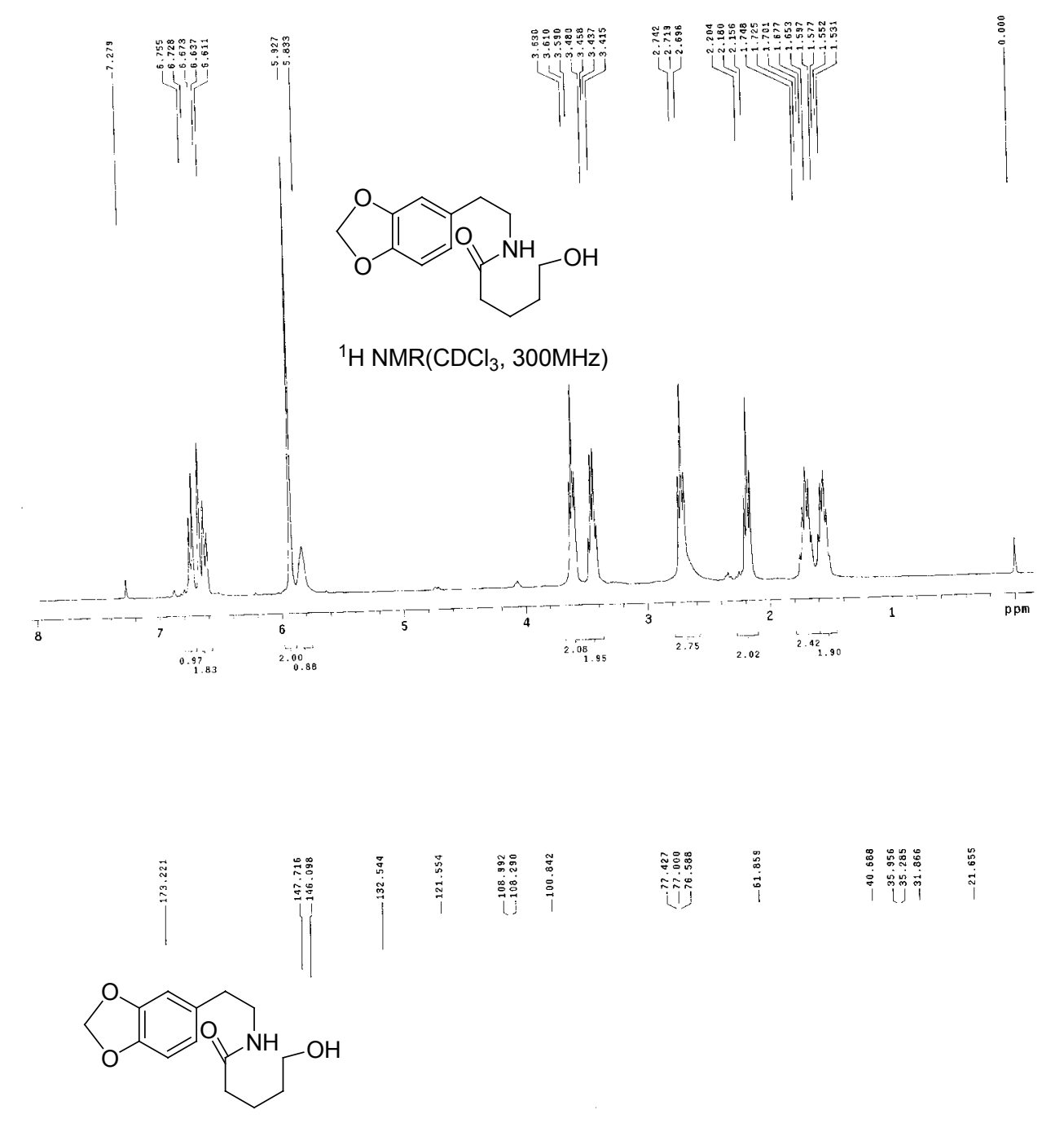

$\operatorname{DEPT}\left(135, \mathrm{CDCl}_{3}, 75 \mathrm{MHz}\right)$

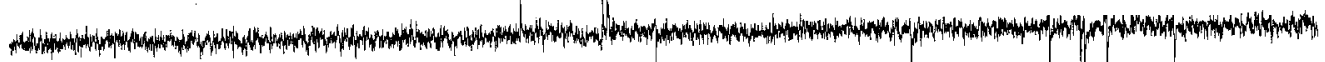
P

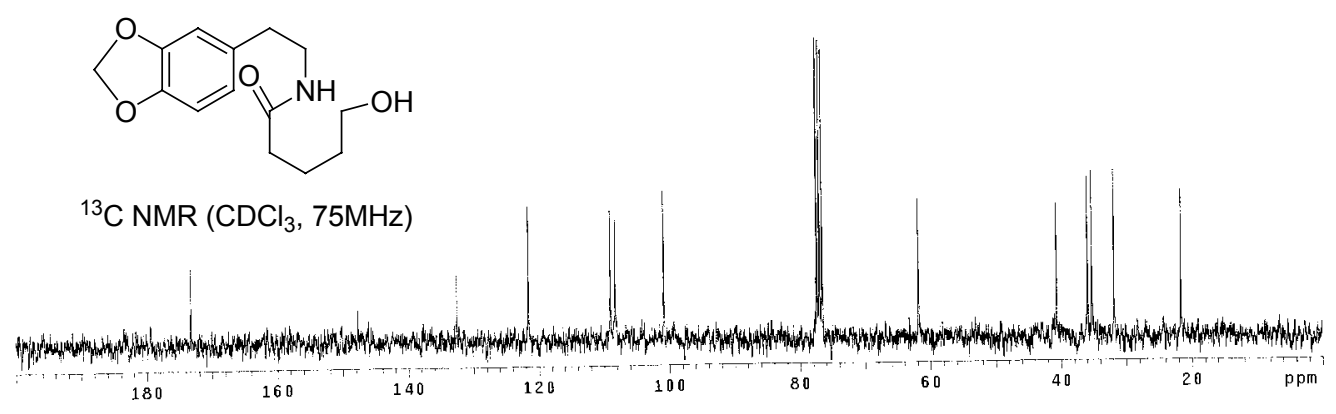



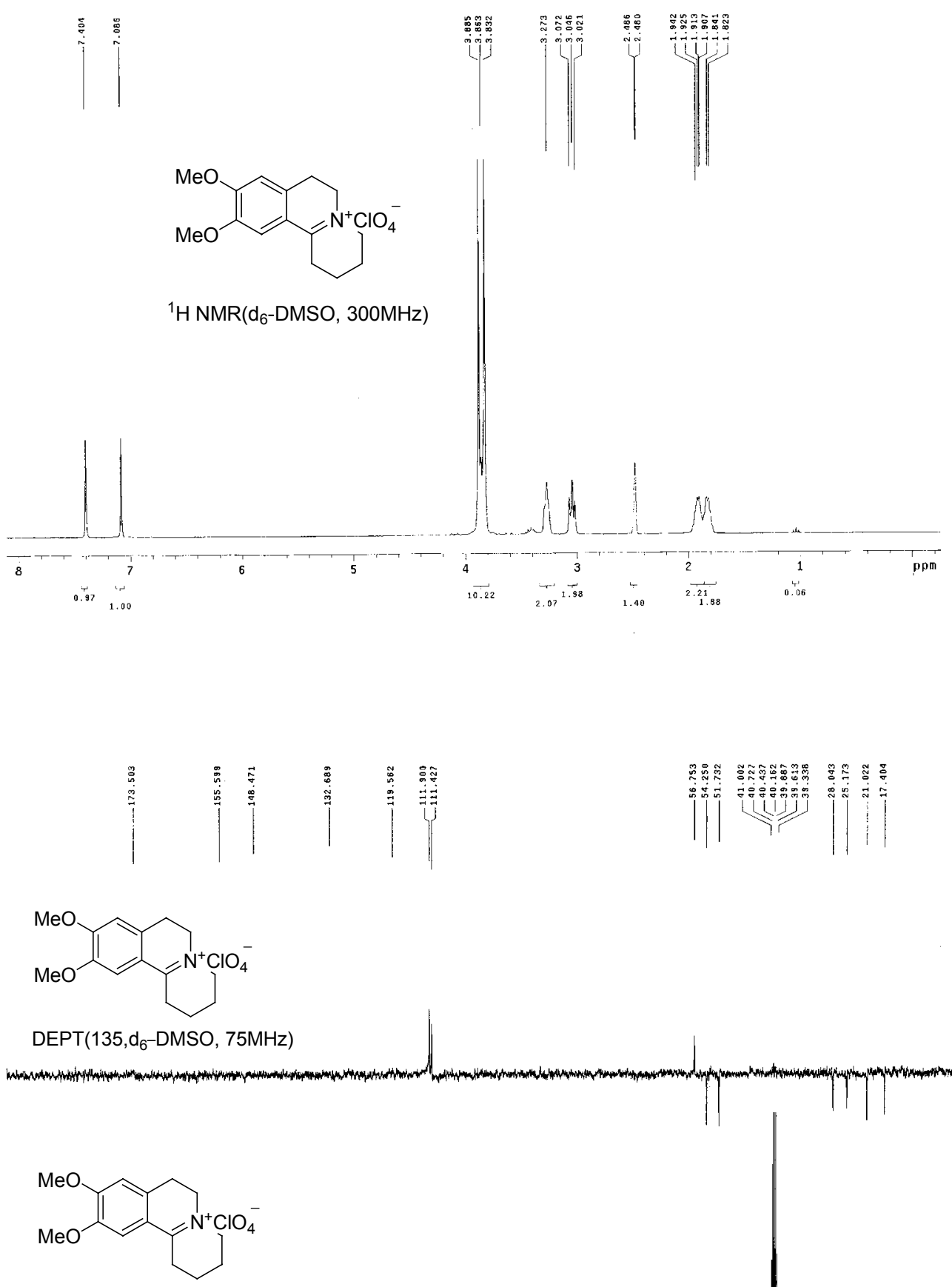

${ }^{13} \mathrm{C}$ NMR $\left(\mathrm{d}_{6}-\mathrm{DMSO}, 75 \mathrm{MHz}\right)$
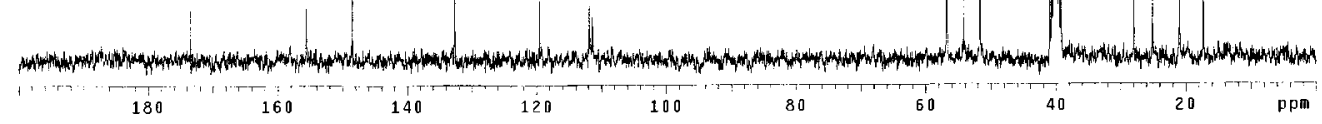

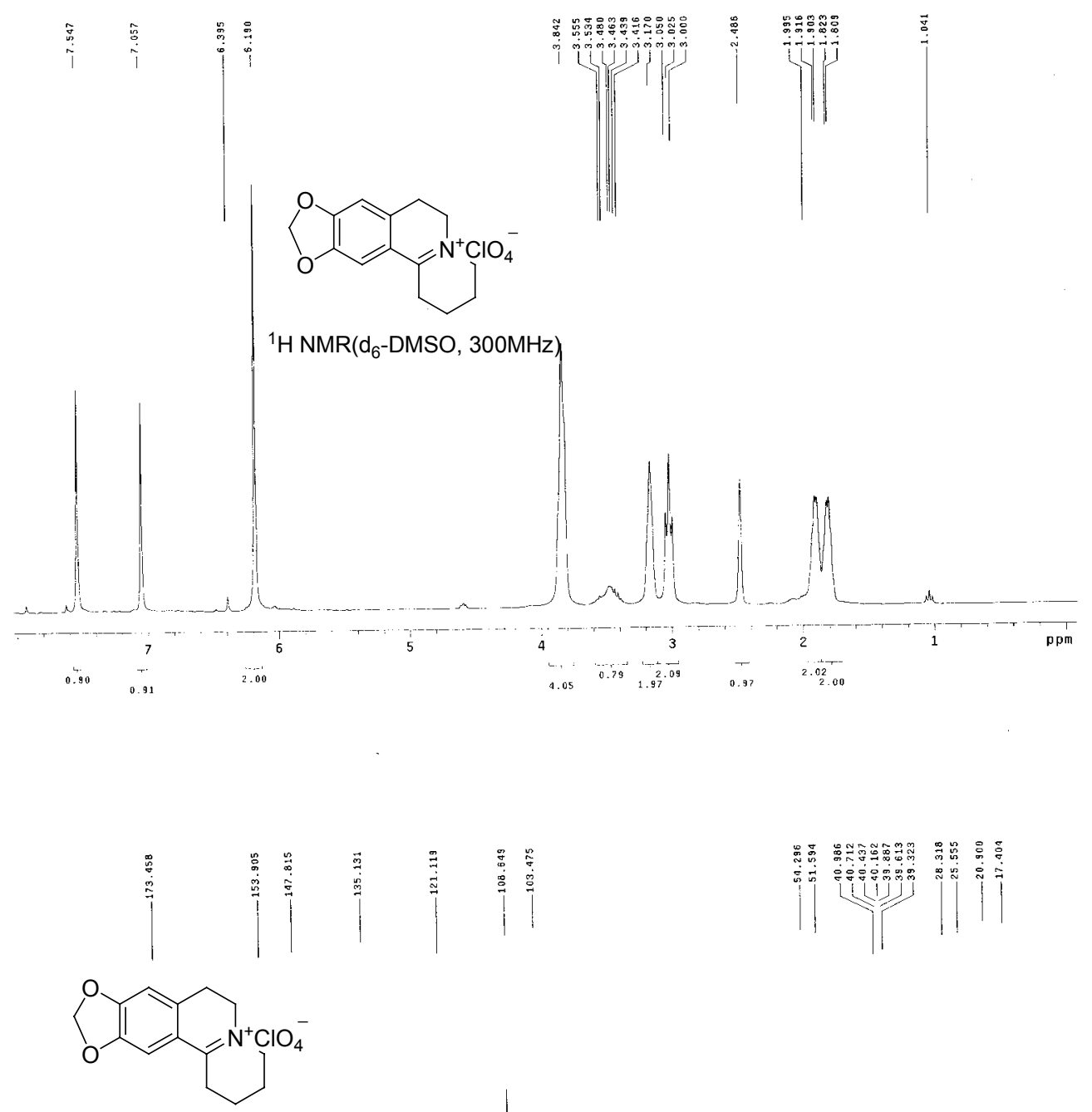

$\operatorname{DEPT}\left(135, \mathrm{~d}_{6}-\mathrm{DMSO}, 75 \mathrm{MHz}\right)$

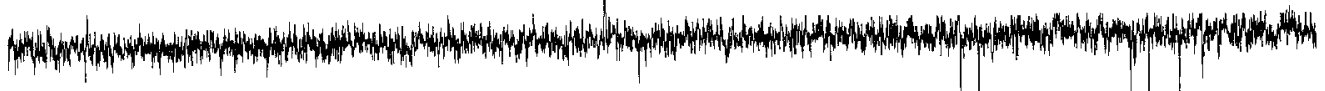

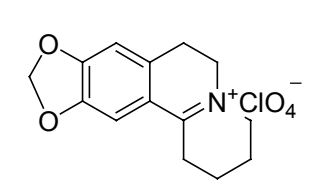

${ }^{13} \mathrm{C}$ NMR $\left(\mathrm{d}_{6}-\mathrm{DMSO}, 75 \mathrm{MHz}\right)$

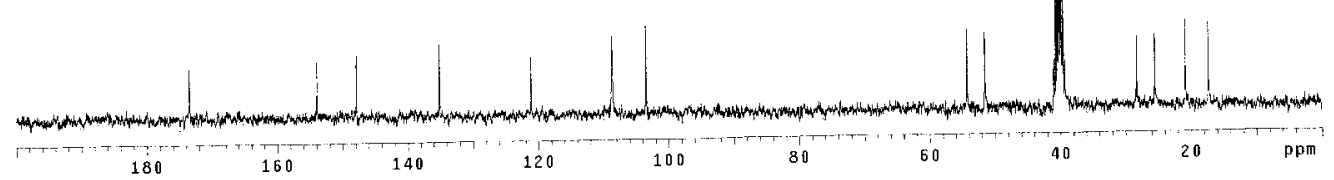


gao- $\mathrm{AABC} 0527$

Archive directory: /exportshone/1iwd/unmrsys/data
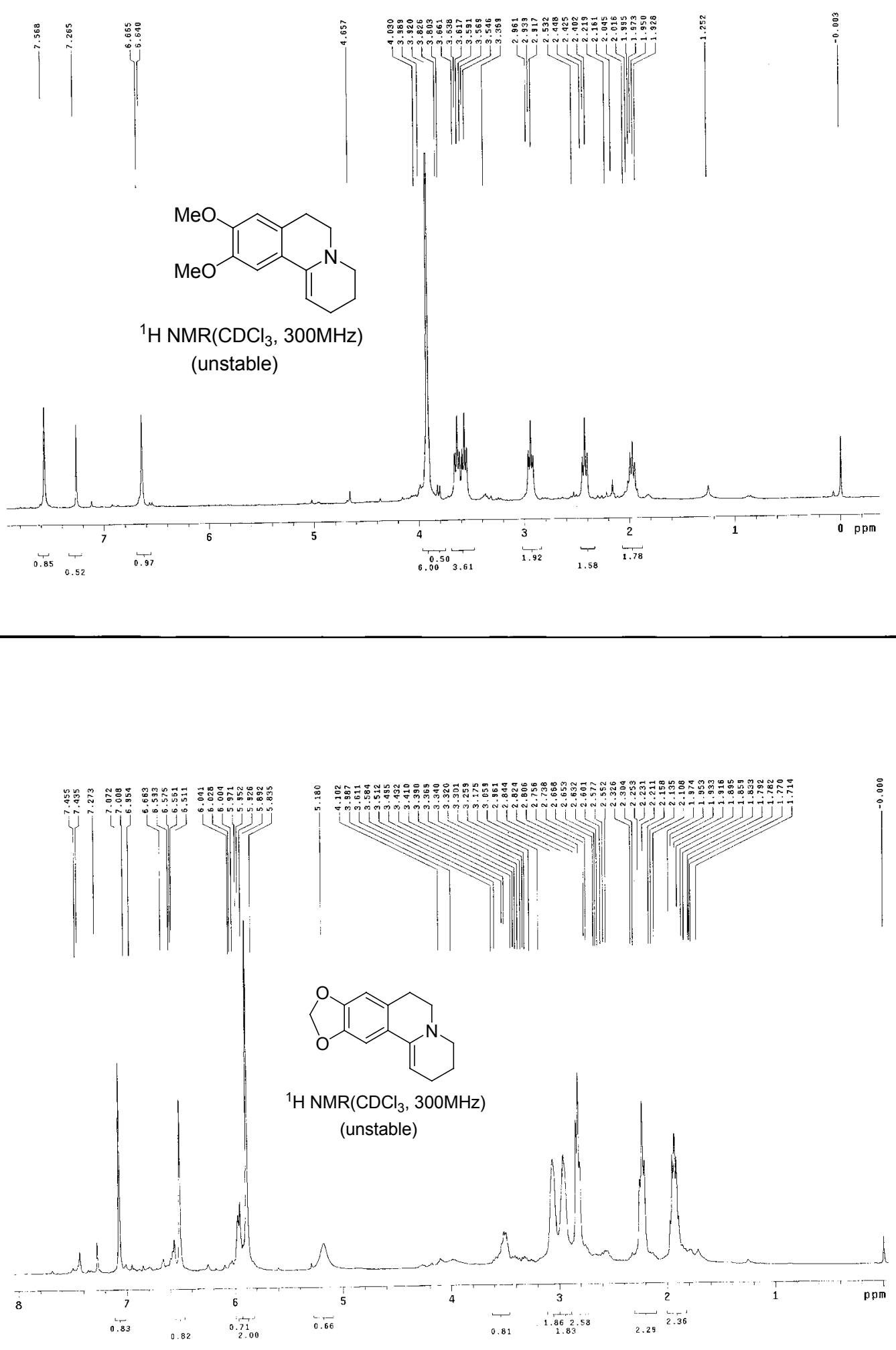


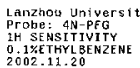

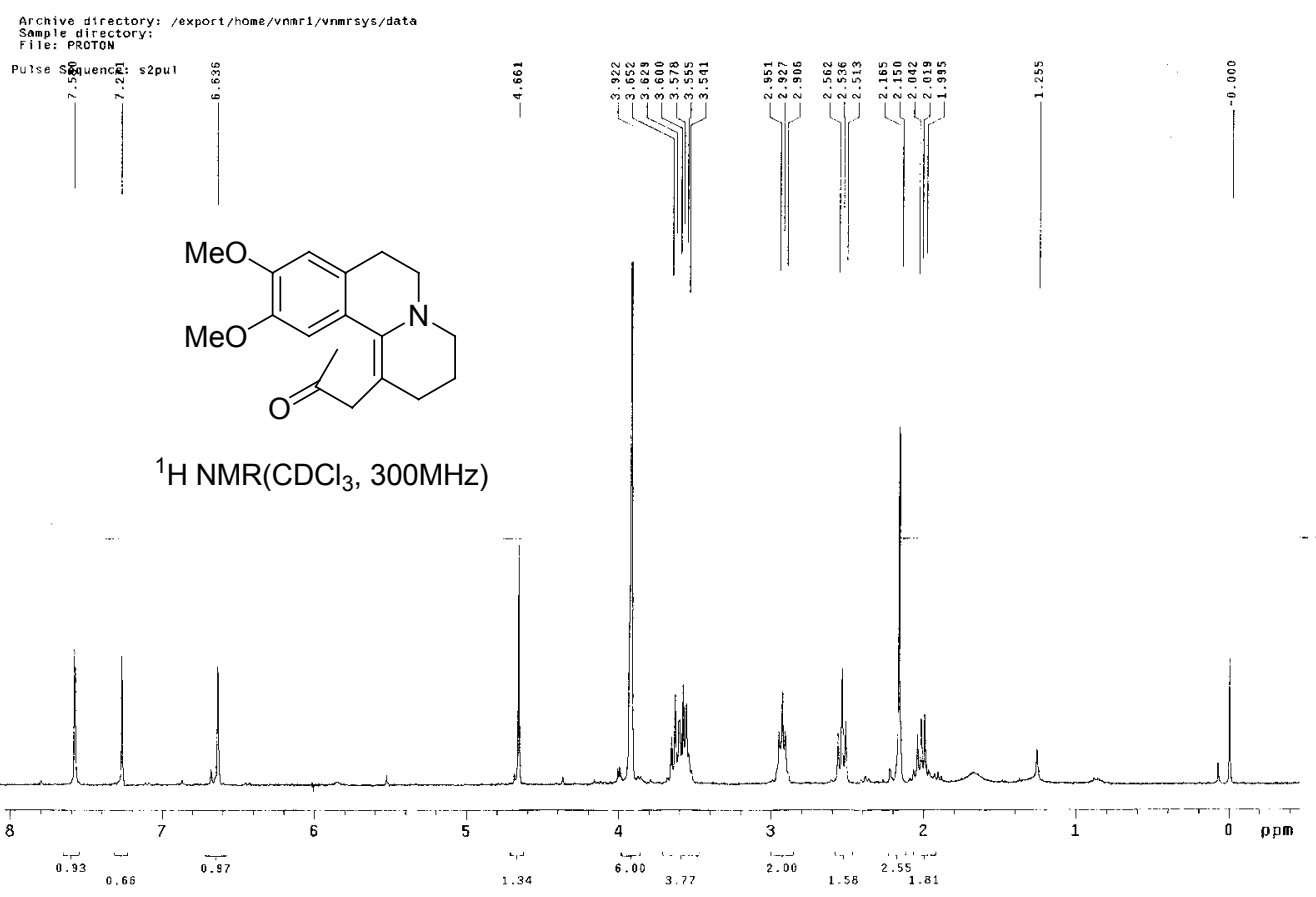

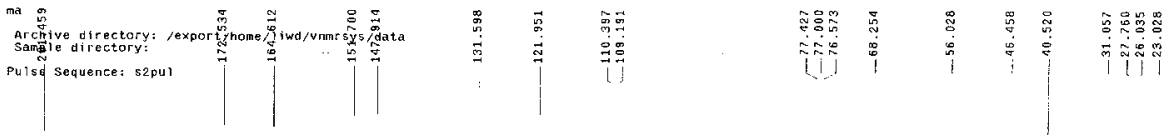

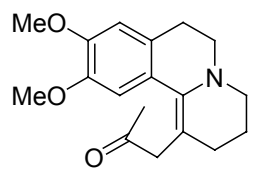

$\mathrm{DEPT}(135, \mathrm{CDCl} 3,75 \mathrm{MHz})$

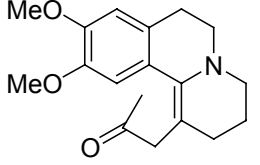

${ }^{13} \mathrm{C} \mathrm{NMR}\left(\mathrm{CDCl}_{3}, 75 \mathrm{MHz}\right)$
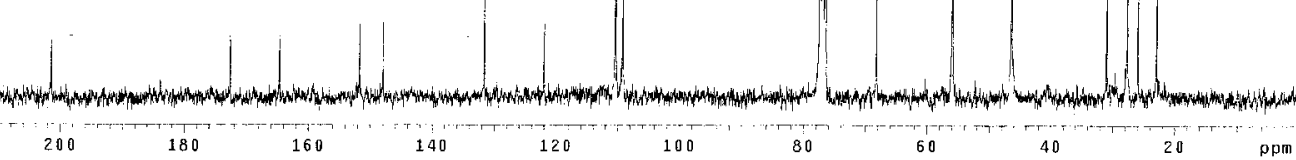


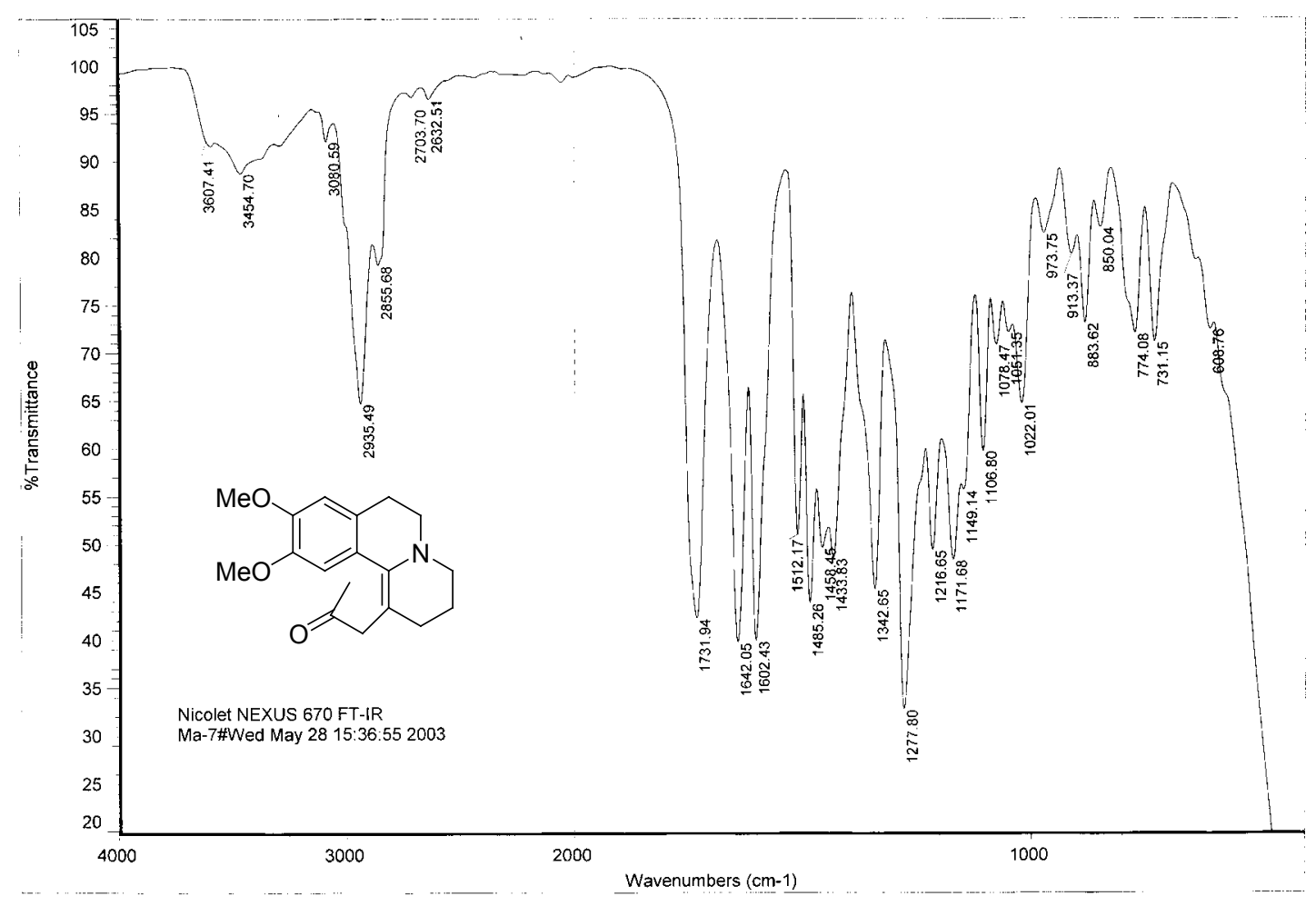

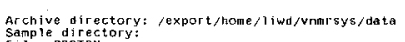

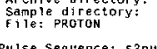

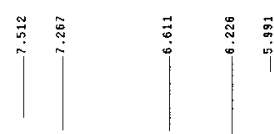
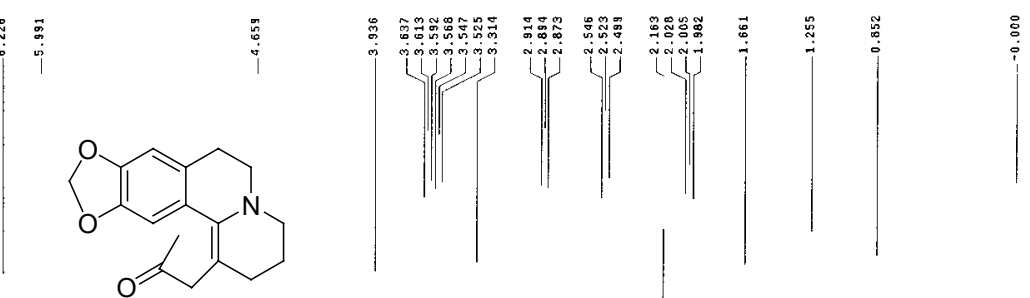

${ }^{1} \mathrm{H} \mathrm{NMR}\left(\mathrm{CDCl}_{3}, 300 \mathrm{MHz}\right)$

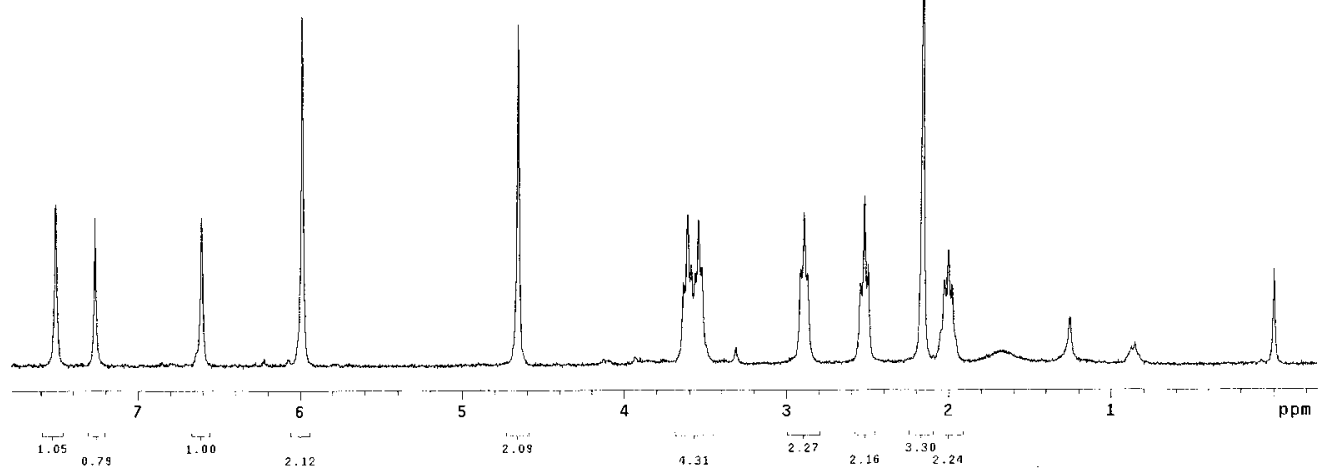



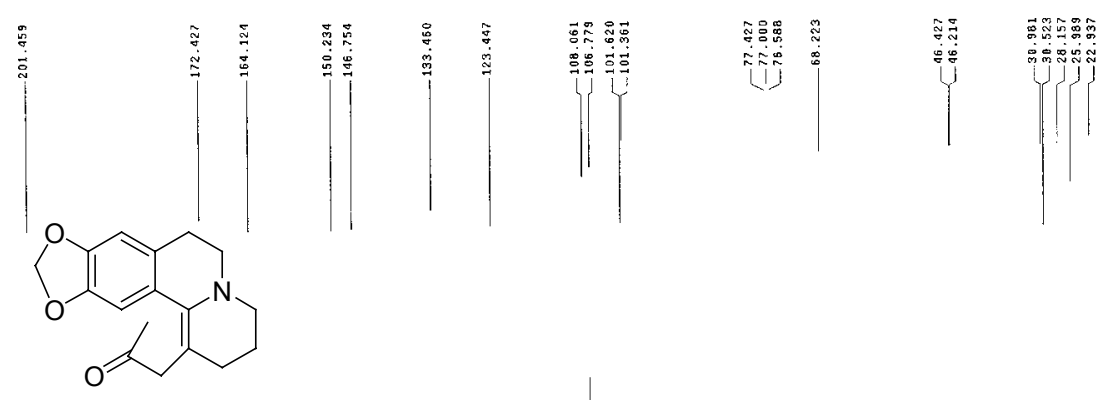

$\operatorname{DEPT}\left(135, \mathrm{CDCl}_{3}, 75 \mathrm{MHz}\right)$

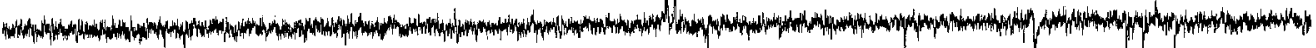
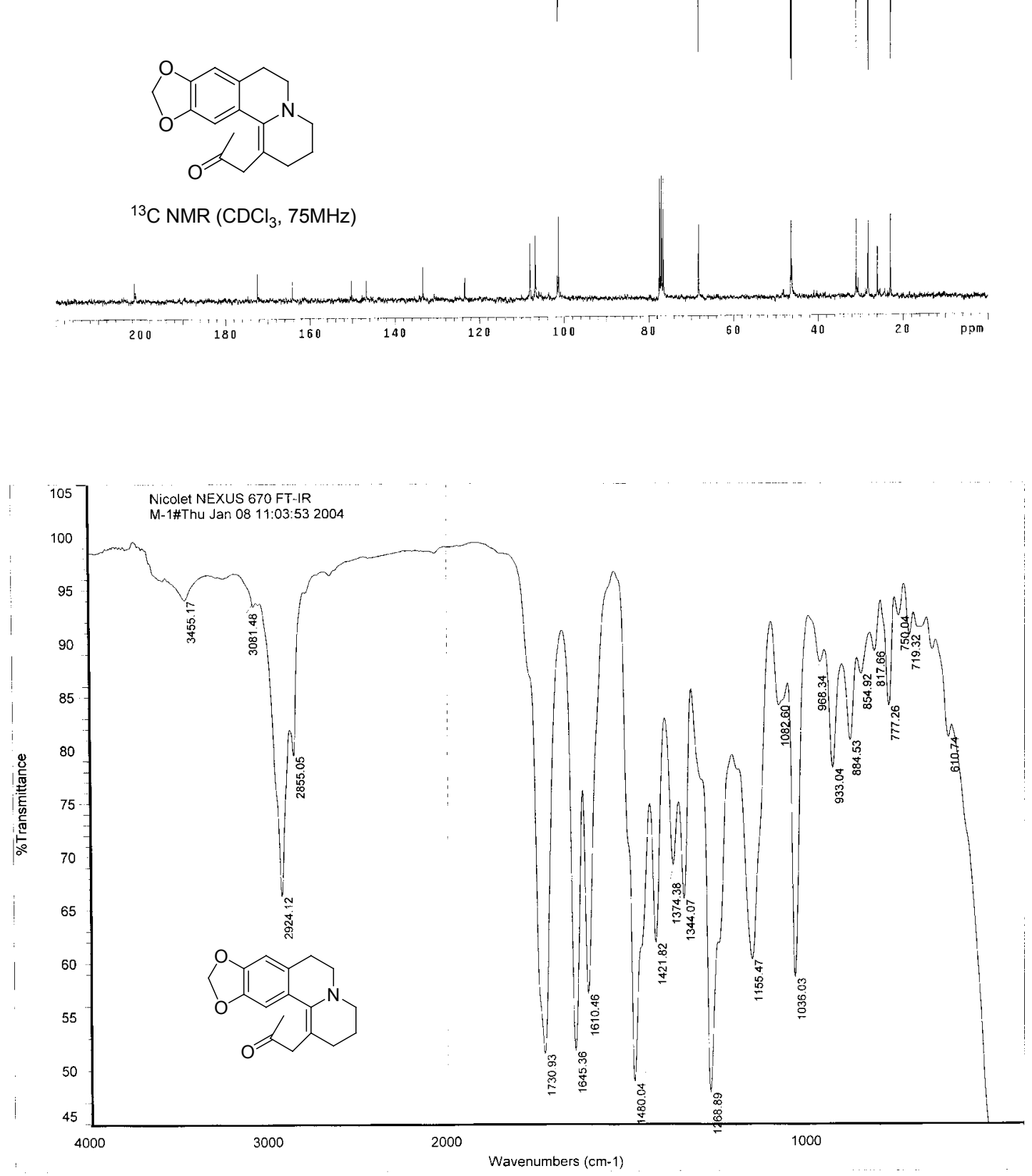

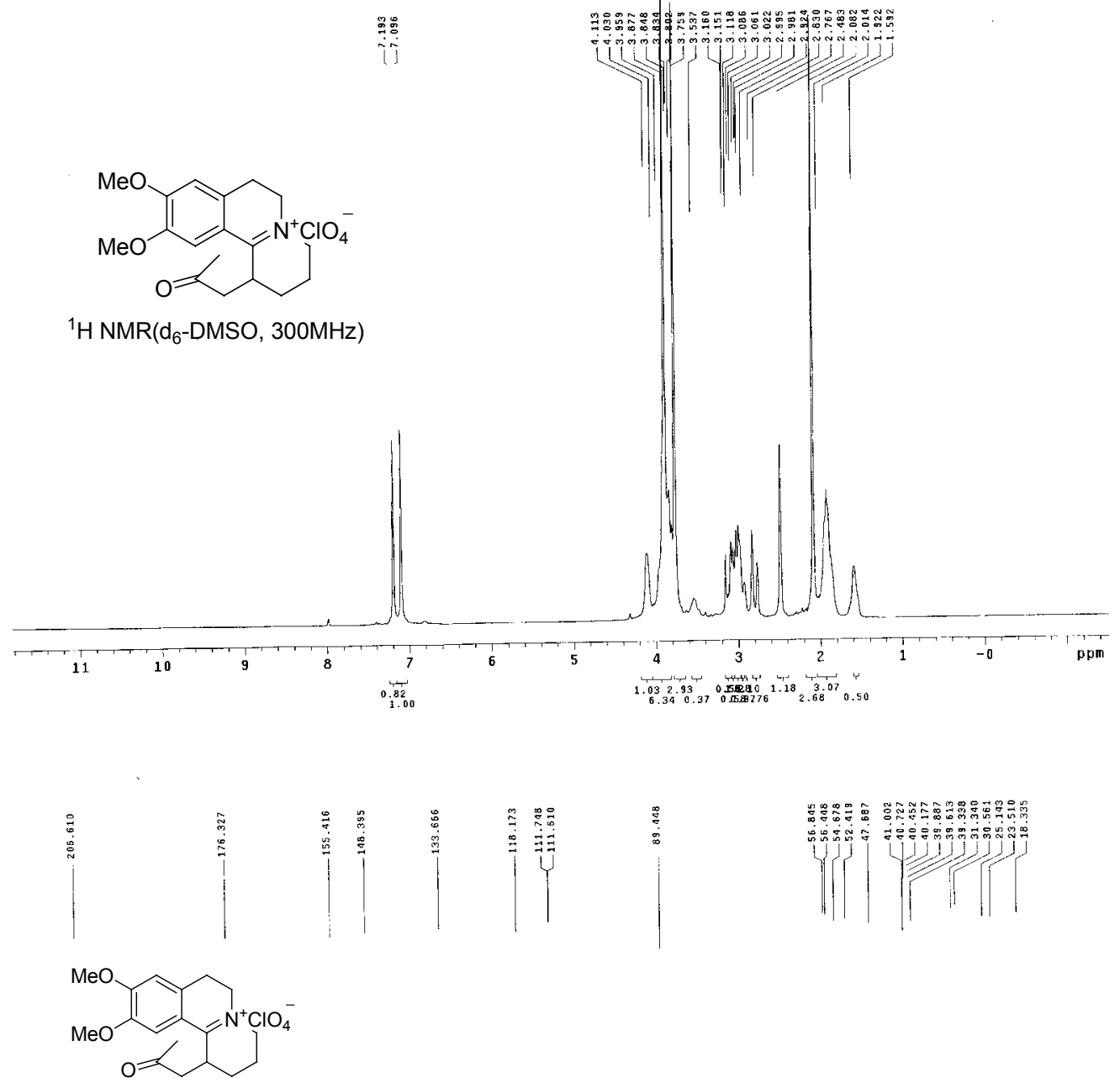

DEPT(135, $\mathrm{d}_{6}$-DMSO, 75MHz)
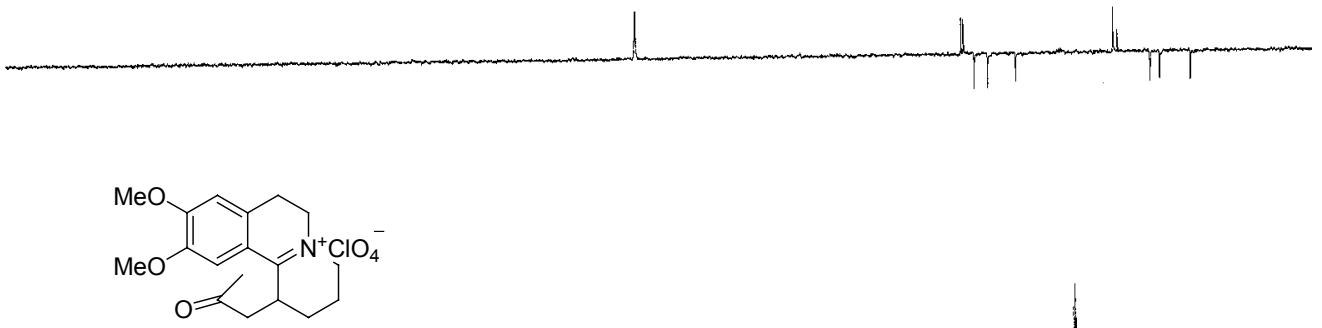

${ }^{13} \mathrm{C}$ NMR $\left(\mathrm{d}_{6}\right.$-DMSO, $\left.75 \mathrm{MHz}\right)$

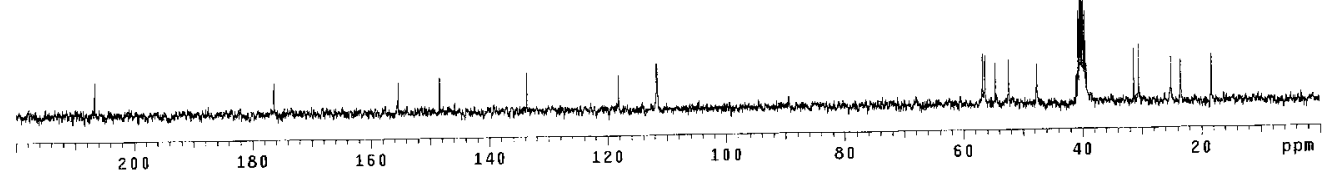




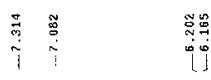
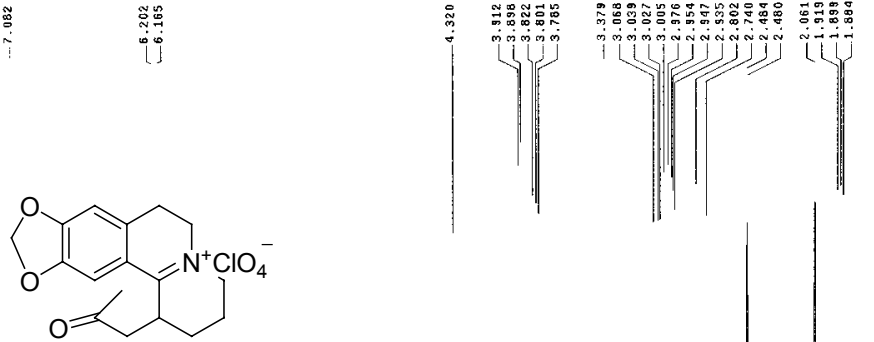

${ }^{1} \mathrm{H} \operatorname{NMR}\left(\mathrm{d}_{6}-\mathrm{DMSO}, 300 \mathrm{MHz}\right)$
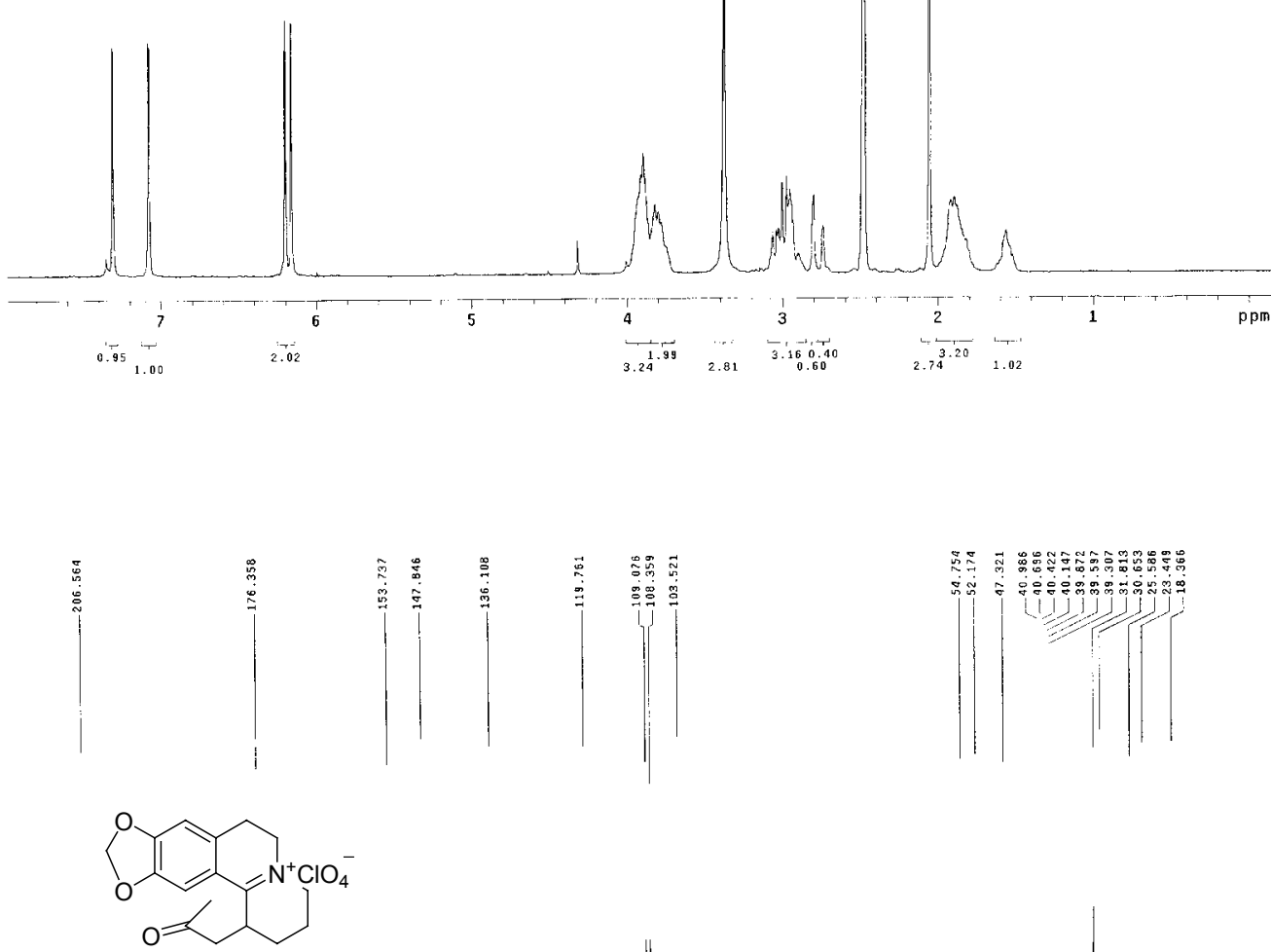

DEPT(135, $\left.\mathrm{d}_{6}-\mathrm{DMSO}, 75 \mathrm{MHz}\right)$
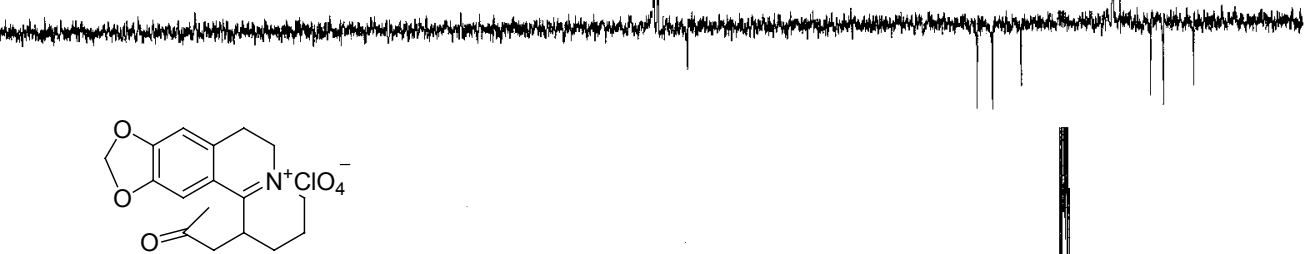

${ }^{13} \mathrm{C}$ NMR $\left(\mathrm{d}_{6}\right.$-DMSO, $\left.75 \mathrm{MHz}\right)$

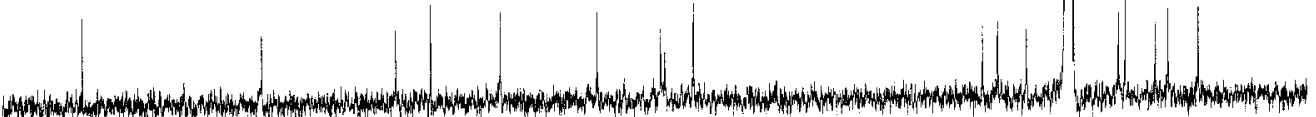
Whothow 

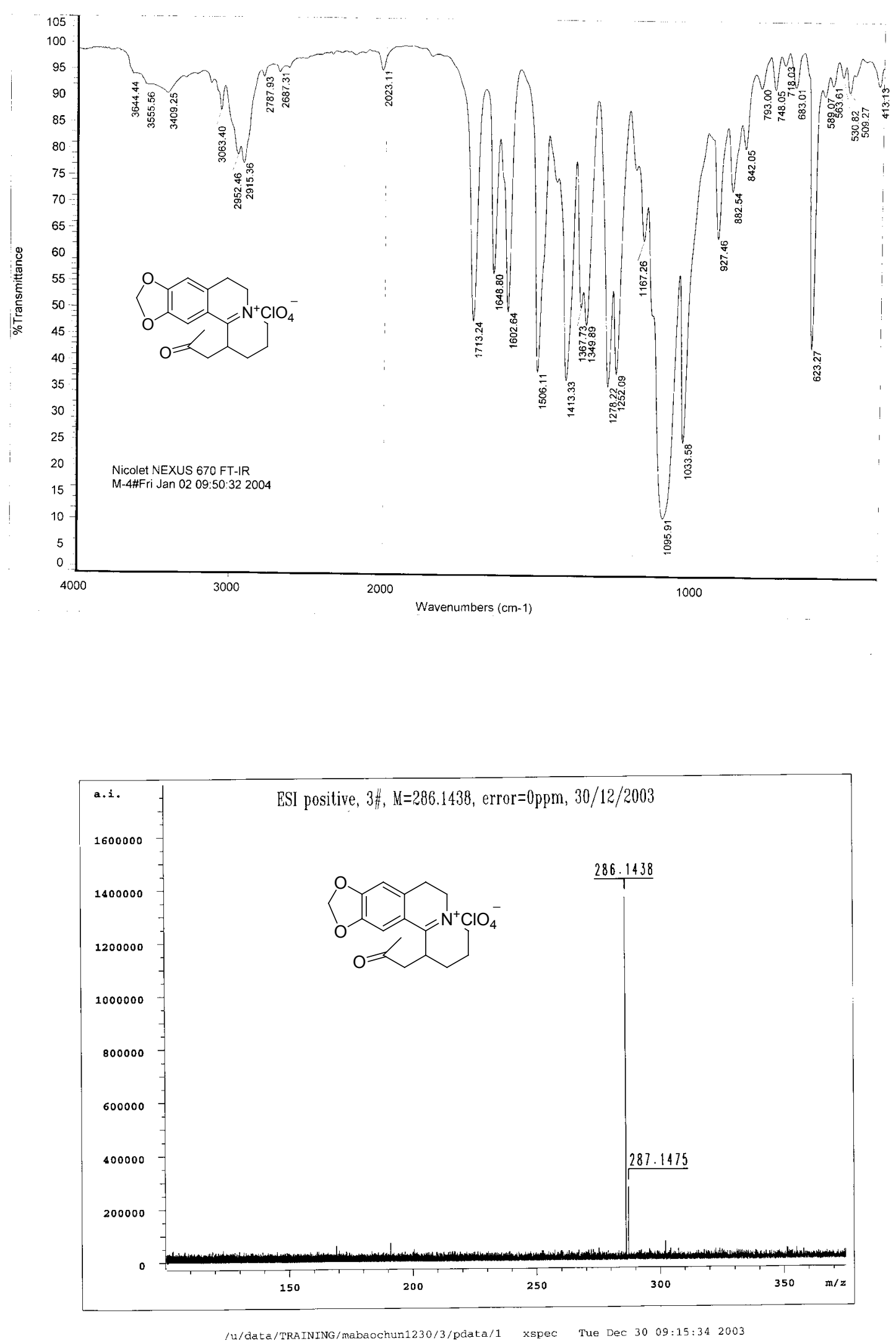

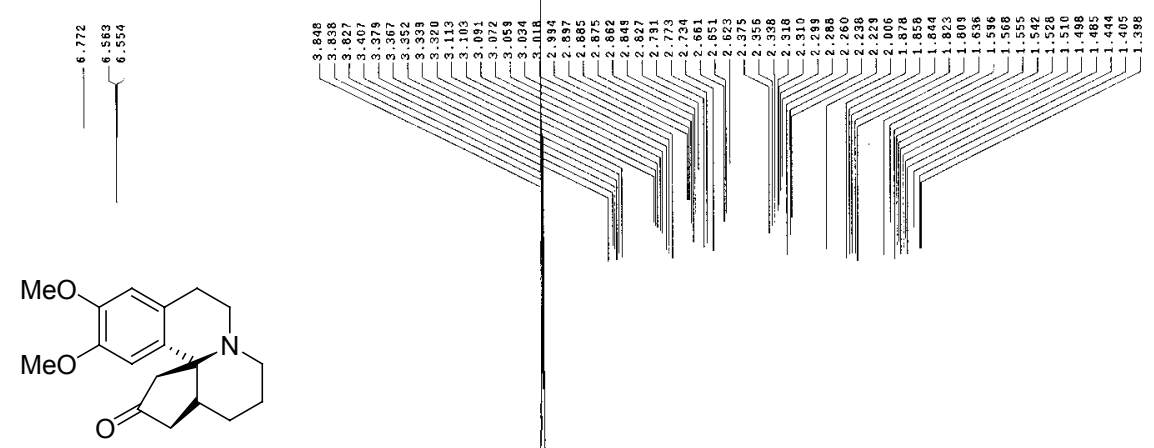

${ }^{1} \mathrm{H} \mathrm{NMR}\left(\mathrm{CDCl}_{3}, 300 \mathrm{MHz}\right)$
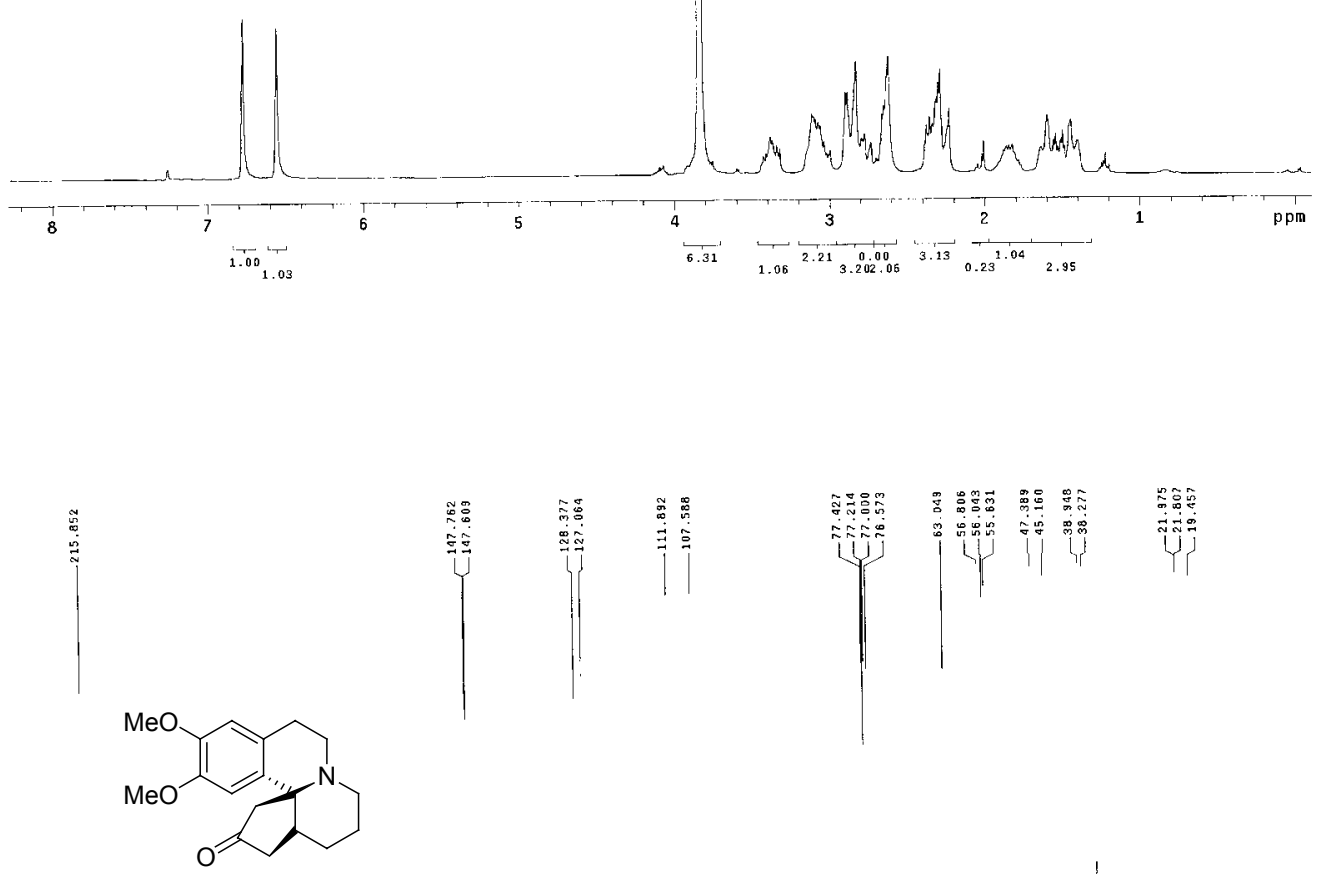

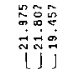

$\operatorname{DEPT}\left(135, \mathrm{CDCl}_{3}, 75 \mathrm{MHz}\right)$

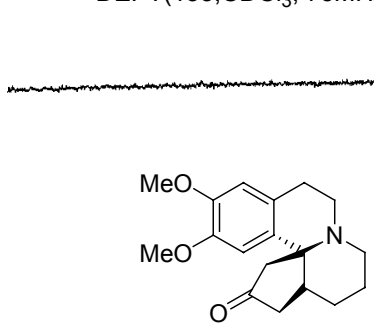

${ }^{13} \mathrm{C} \mathrm{NMR}\left(\mathrm{CDCl}_{3}, 75 \mathrm{MHz}\right)$

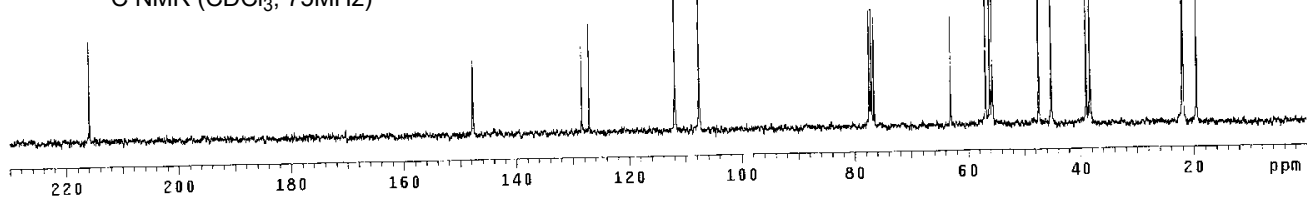



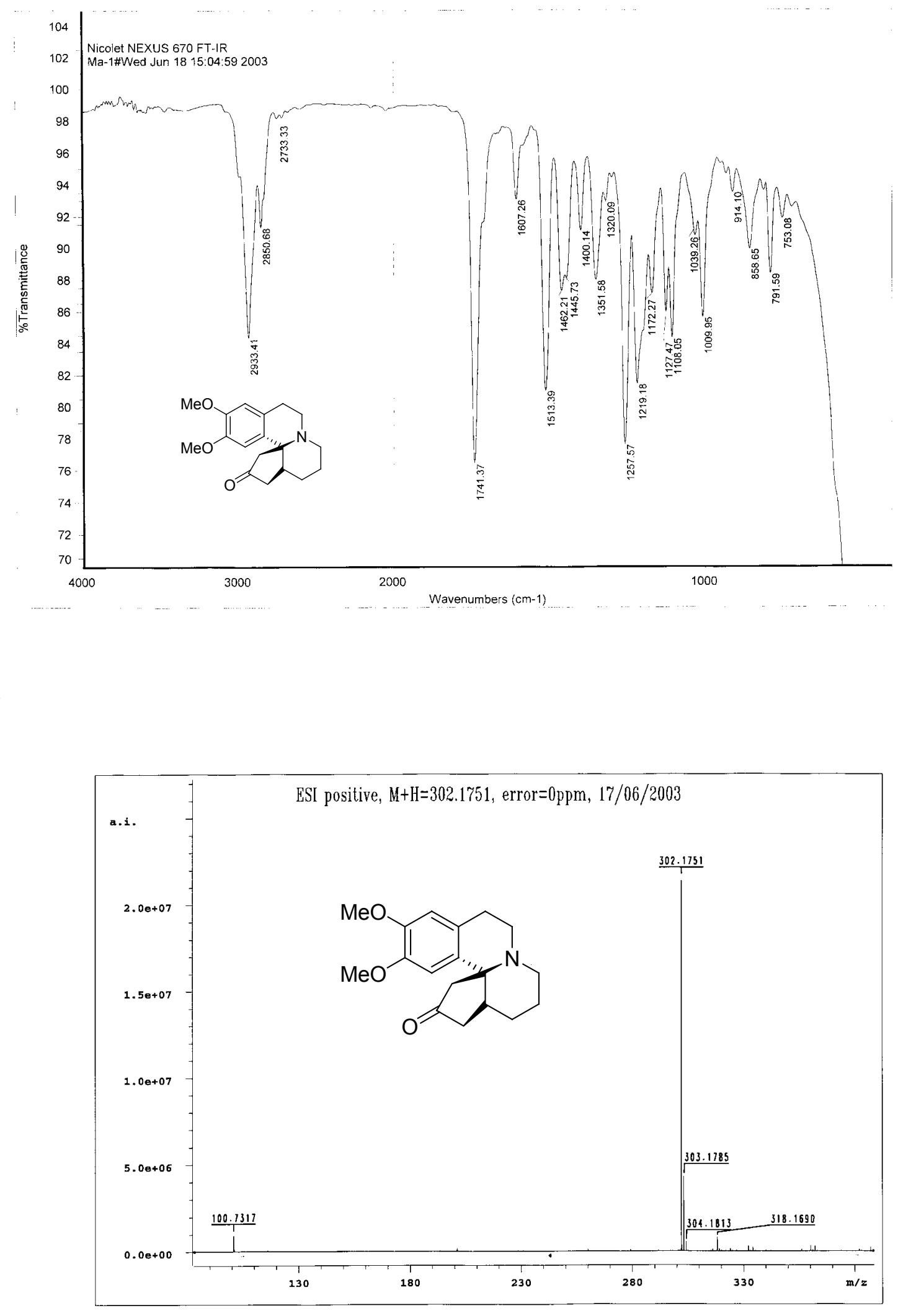

/u/data/TRAINING/mabaochun0617/1/pdata/1 xspec Tue Jun 17 09:42:16 2003 

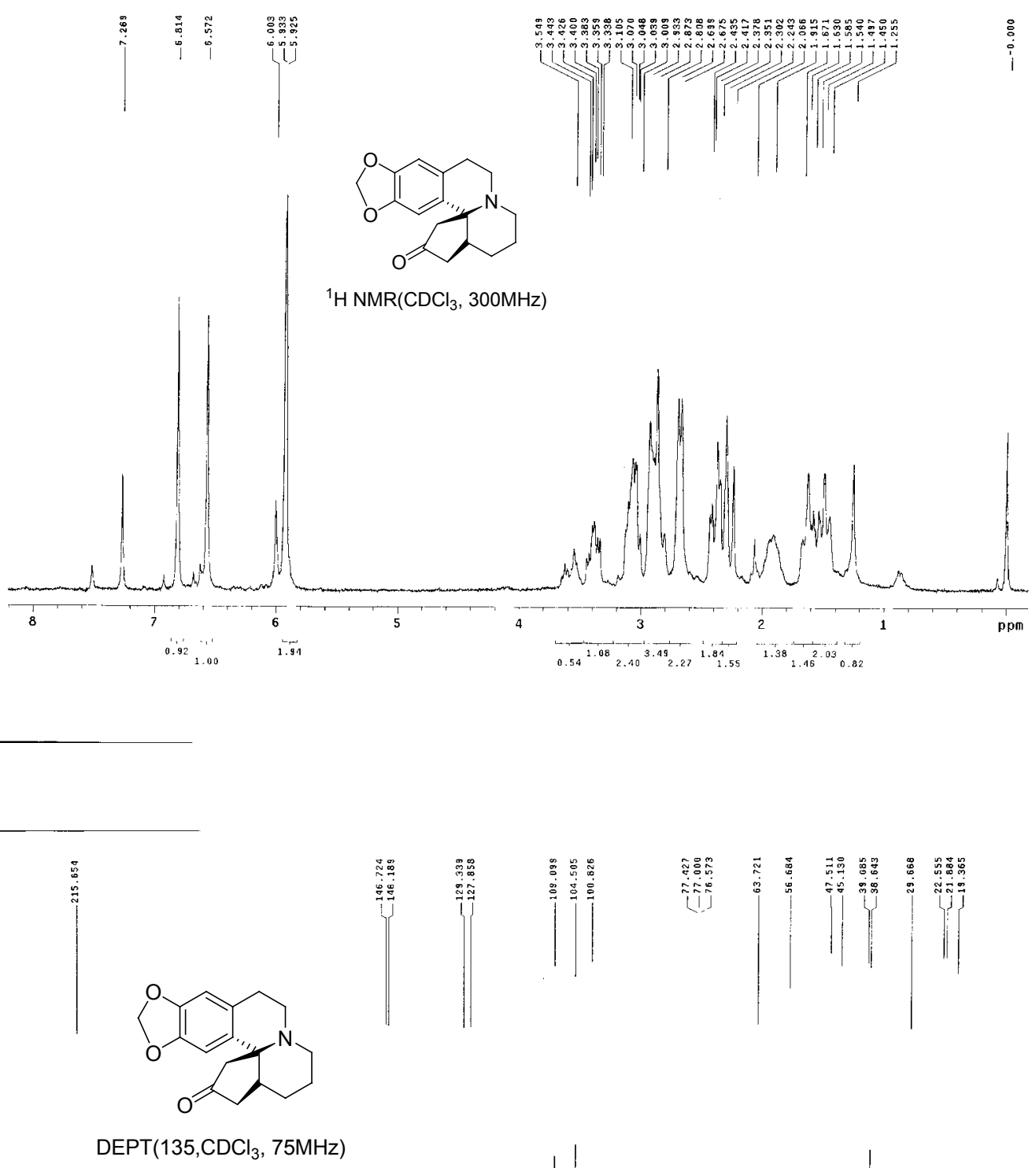

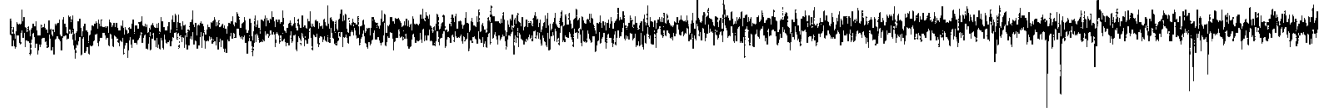

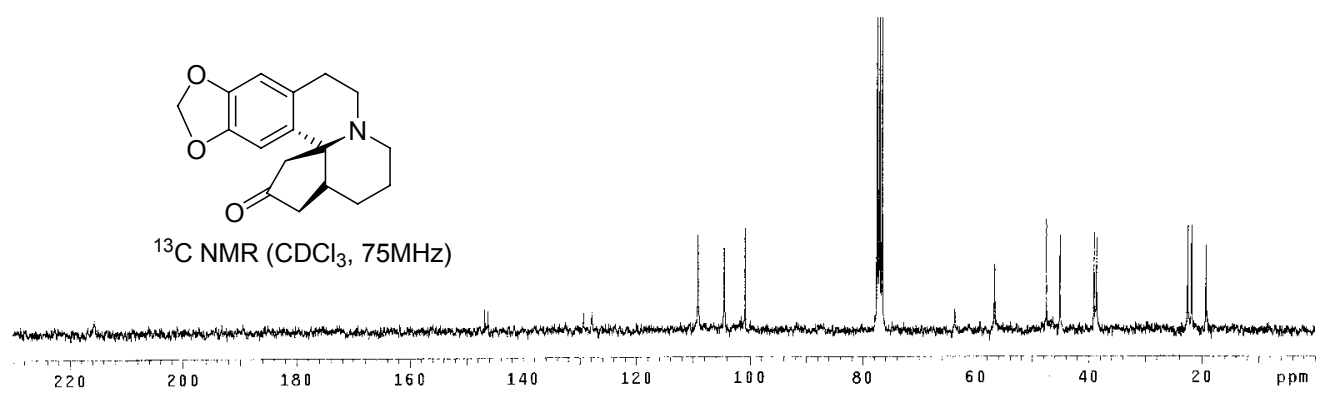



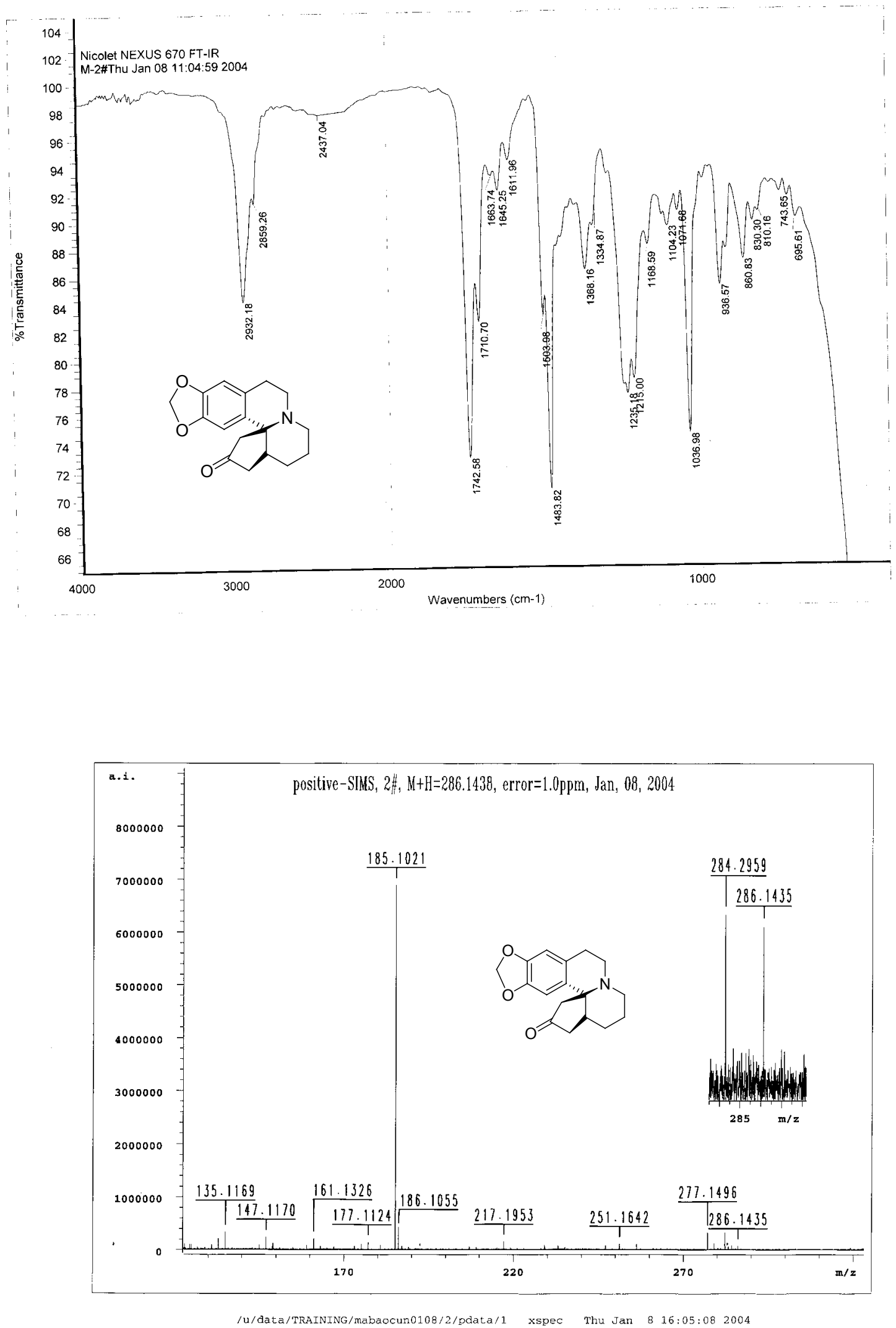

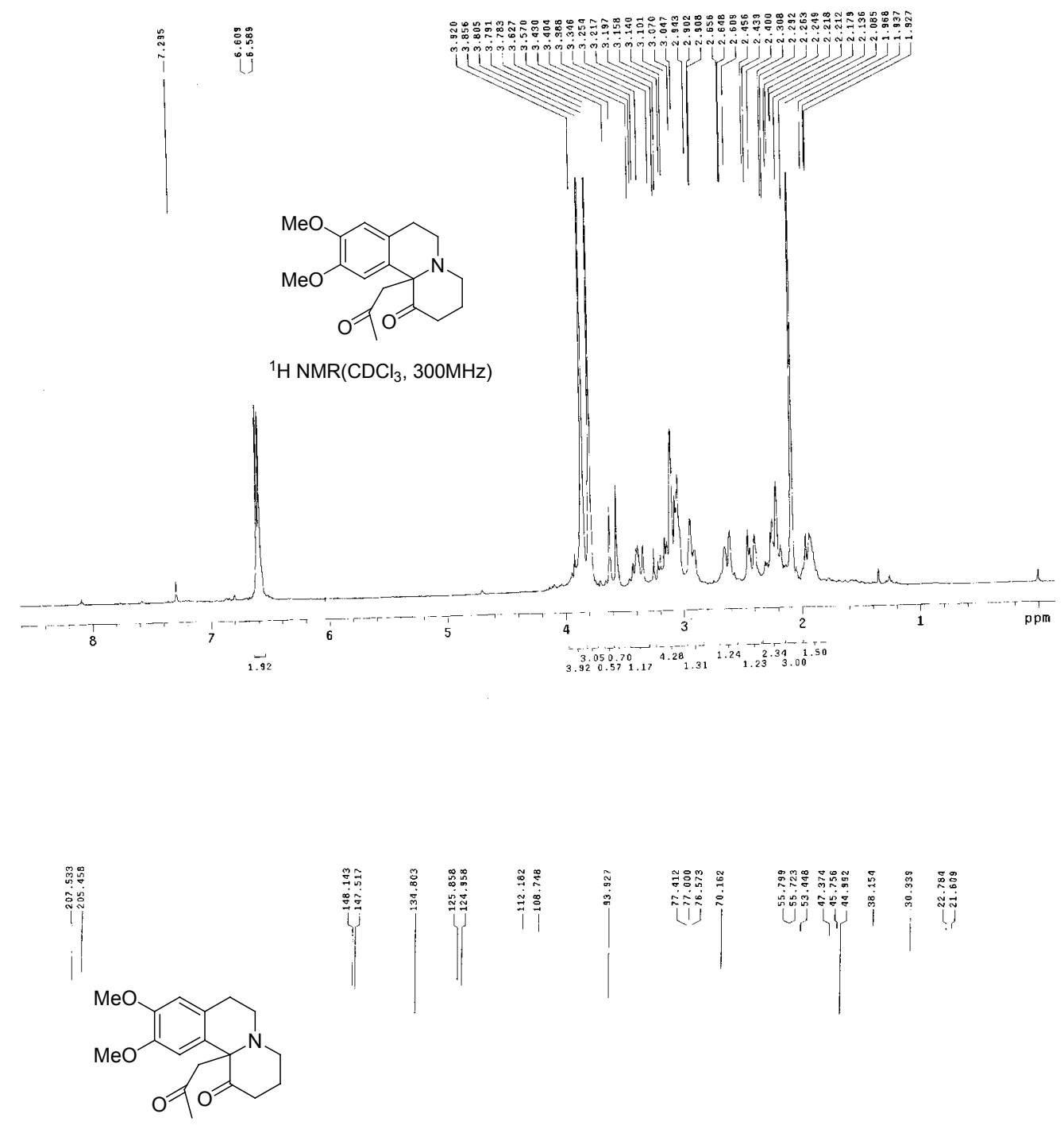

$\operatorname{DEPT}\left(135, \mathrm{CDCl}_{3}, 75 \mathrm{MHz}\right)$

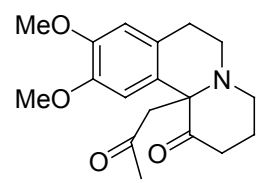

${ }^{13} \mathrm{C} \mathrm{NMR}\left(\mathrm{CDCl}_{3}, 75 \mathrm{MHz}\right)$
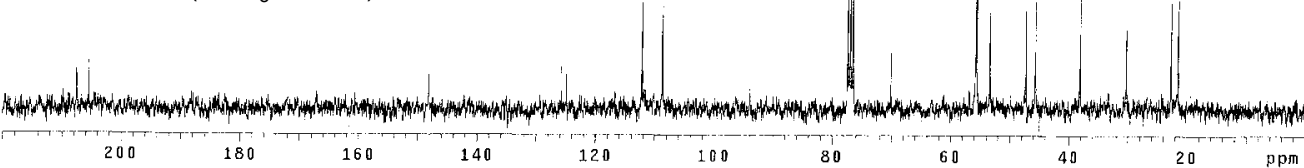

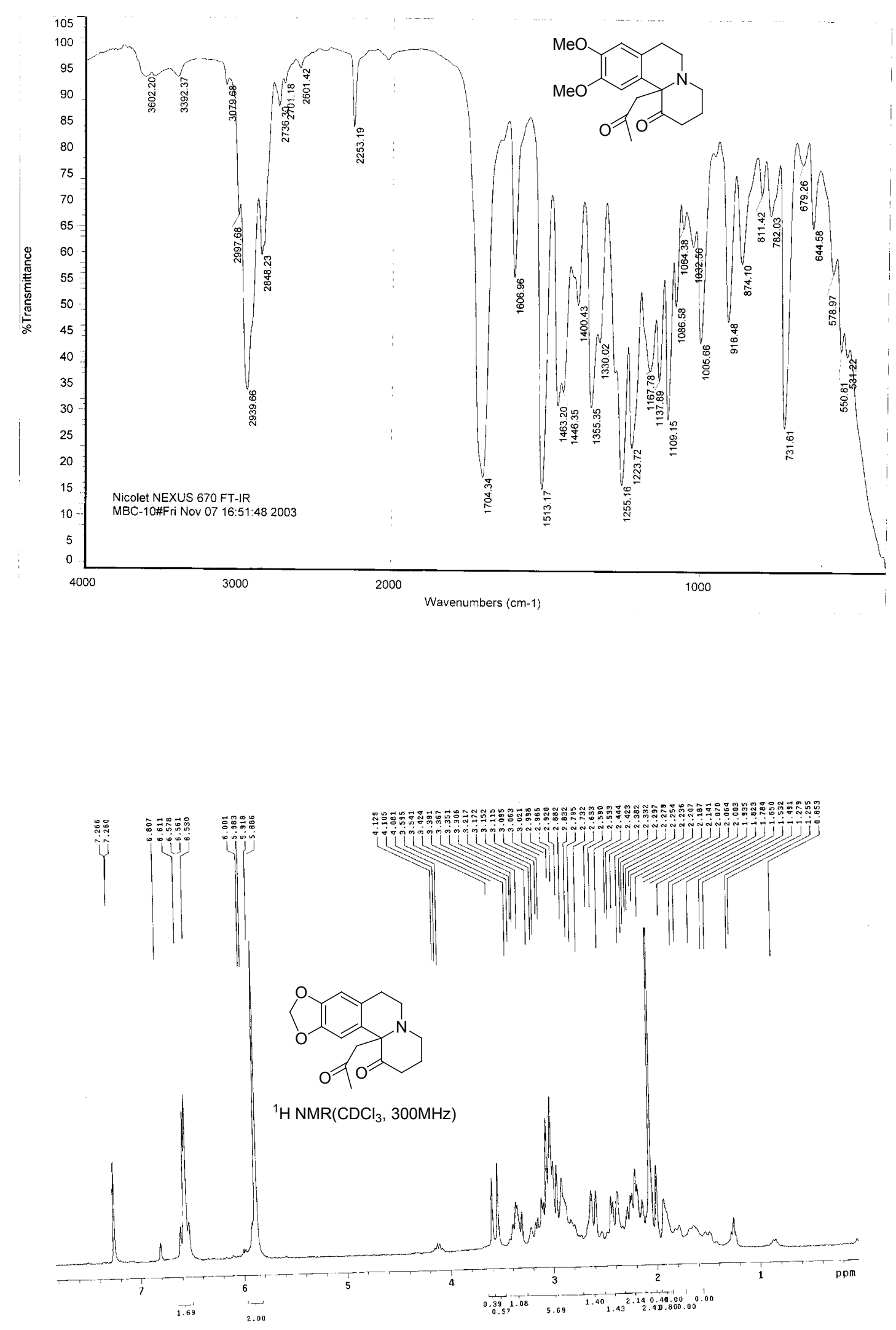

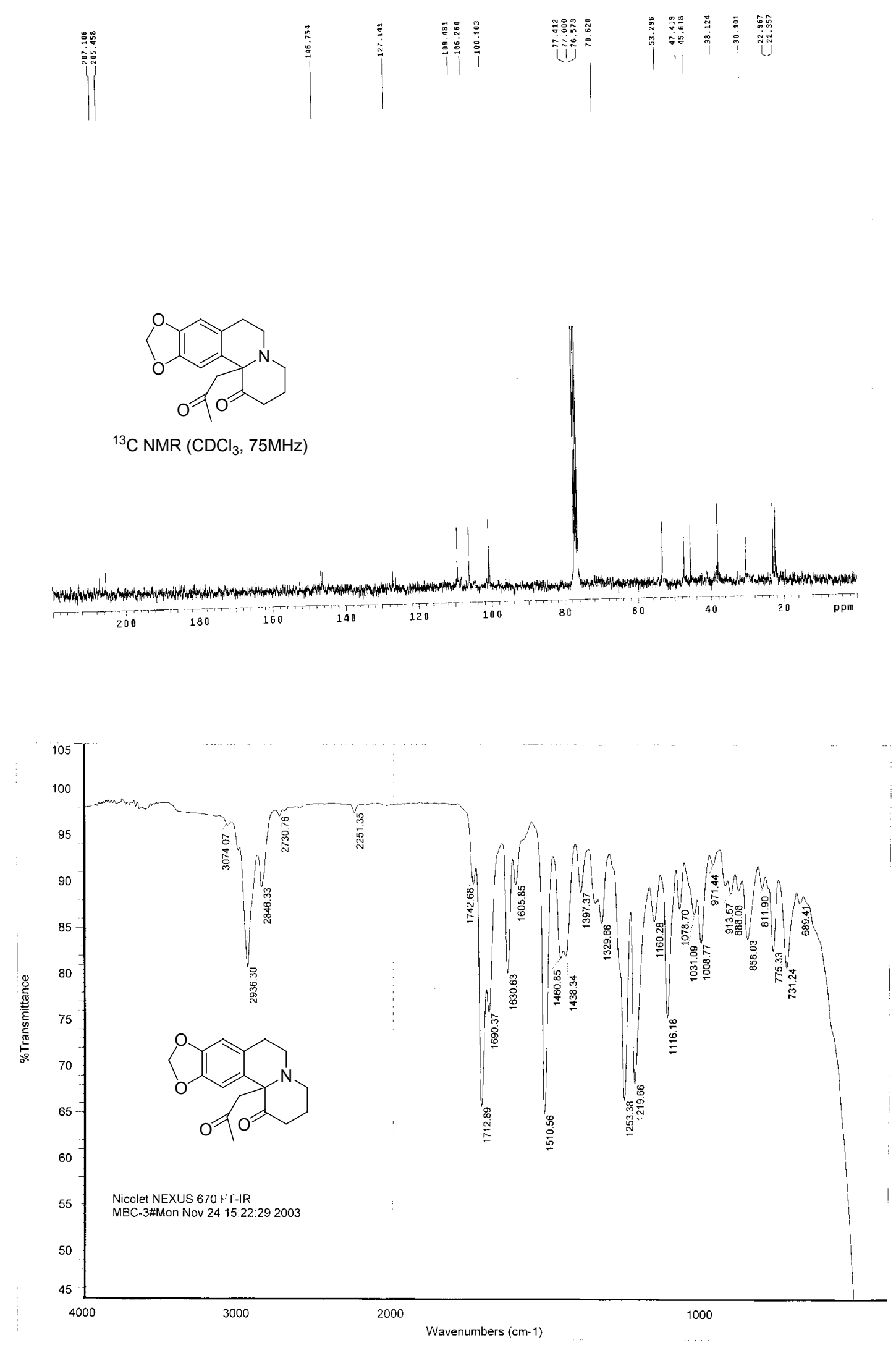

S

19 

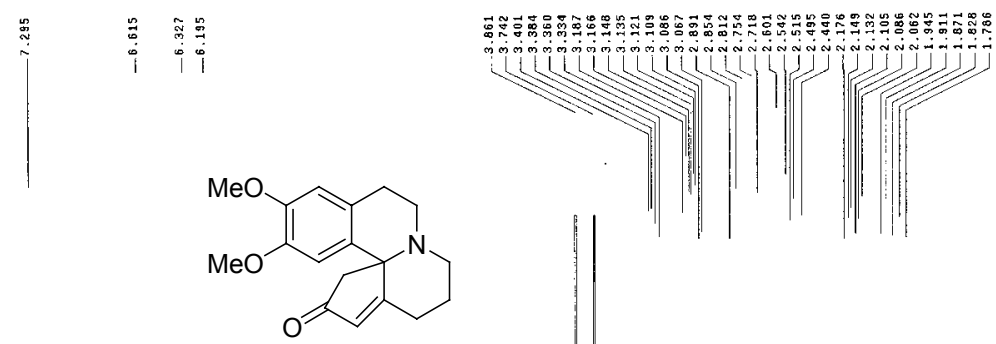

${ }^{1} \mathrm{H} \mathrm{NMR}\left(\mathrm{CDCl}_{3}, 300 \mathrm{MHz}\right)$
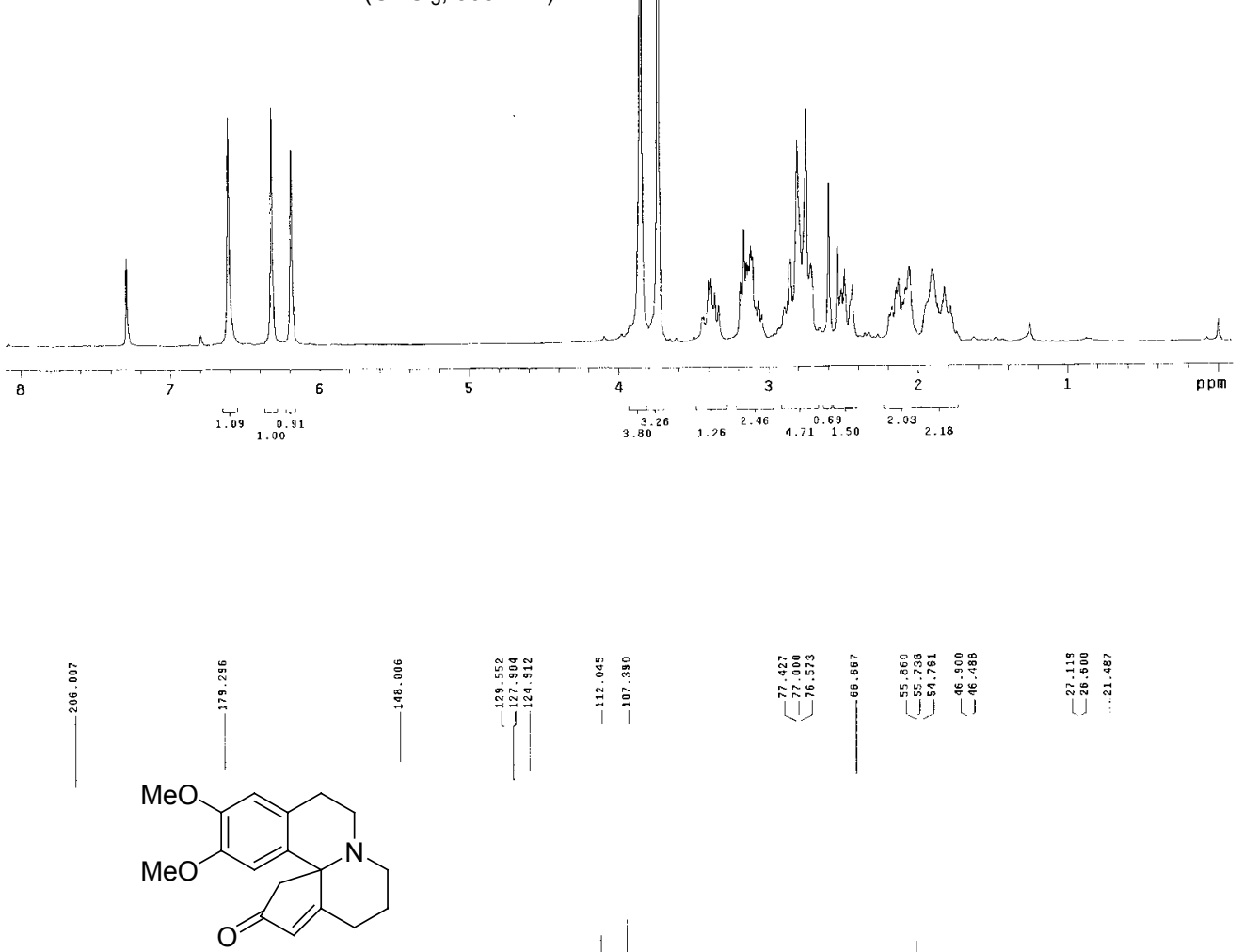

$\operatorname{DEPT}\left(135, \mathrm{CDCl}_{3}, 75 \mathrm{MHz}\right)$
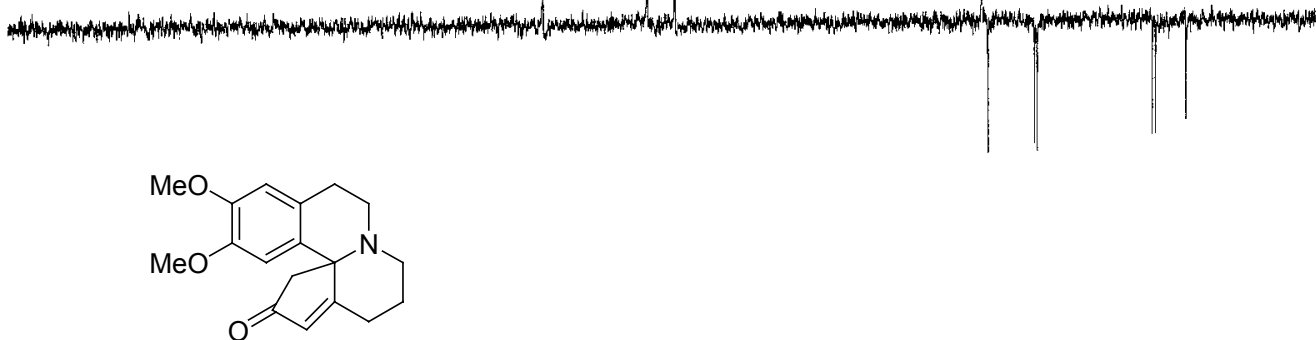

${ }^{13} \mathrm{C}$ NMR $\left(\mathrm{CDCl}_{3}, 75 \mathrm{MHz}\right)$

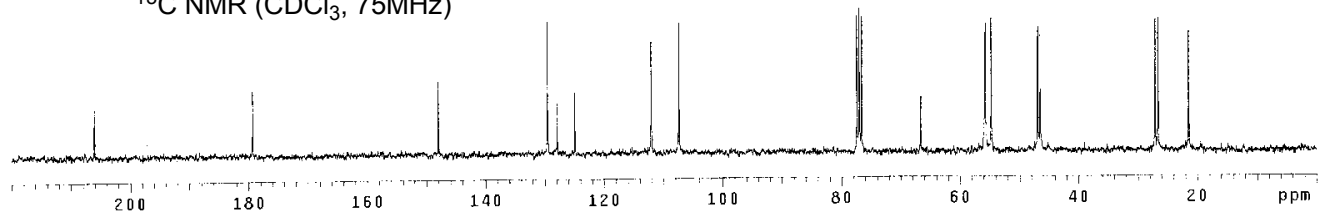



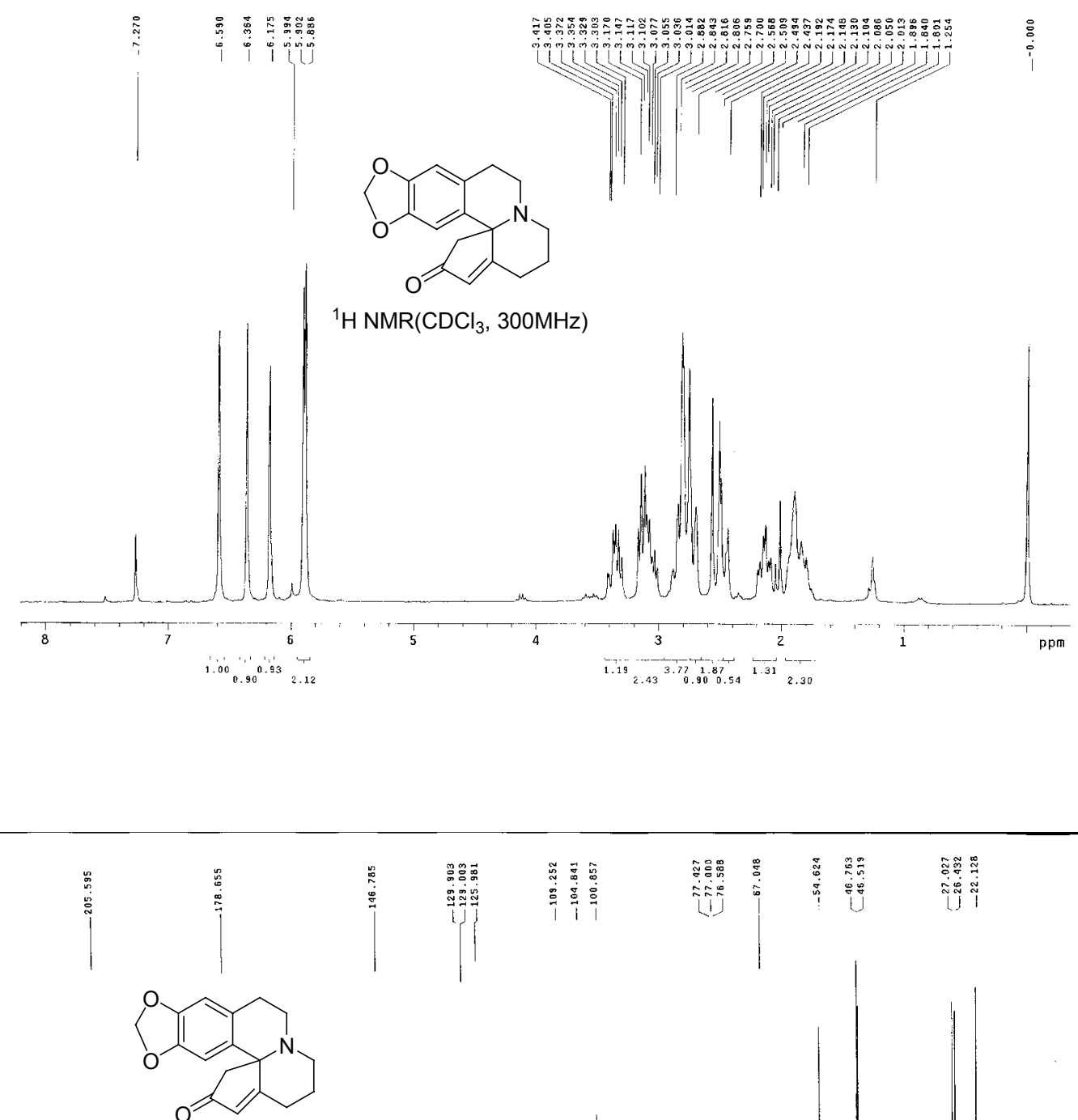

$\operatorname{DEPT}\left(135, \mathrm{CDCl}_{3}, 75 \mathrm{MHz}\right)$

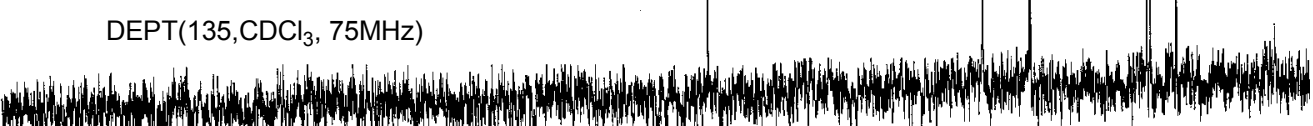

nophy

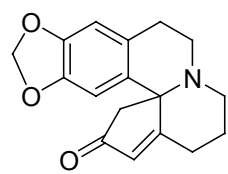

${ }^{13} \mathrm{C} \mathrm{NMR}\left(\mathrm{CDCl}_{3}, 75 \mathrm{MHz}\right)$

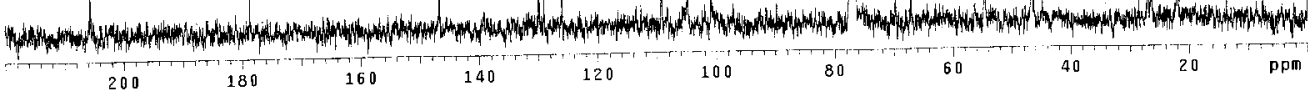

$$
20018010160 \quad 140 \quad 120 \quad 100
$$
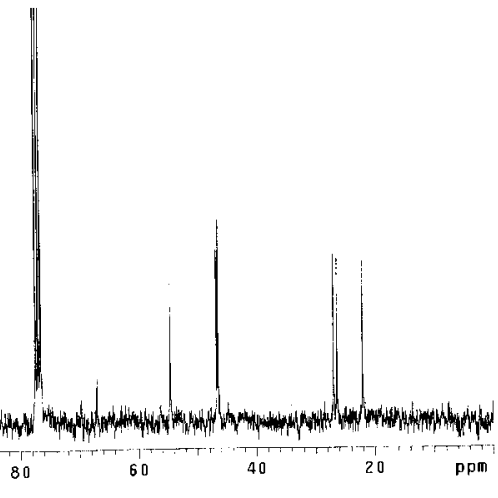


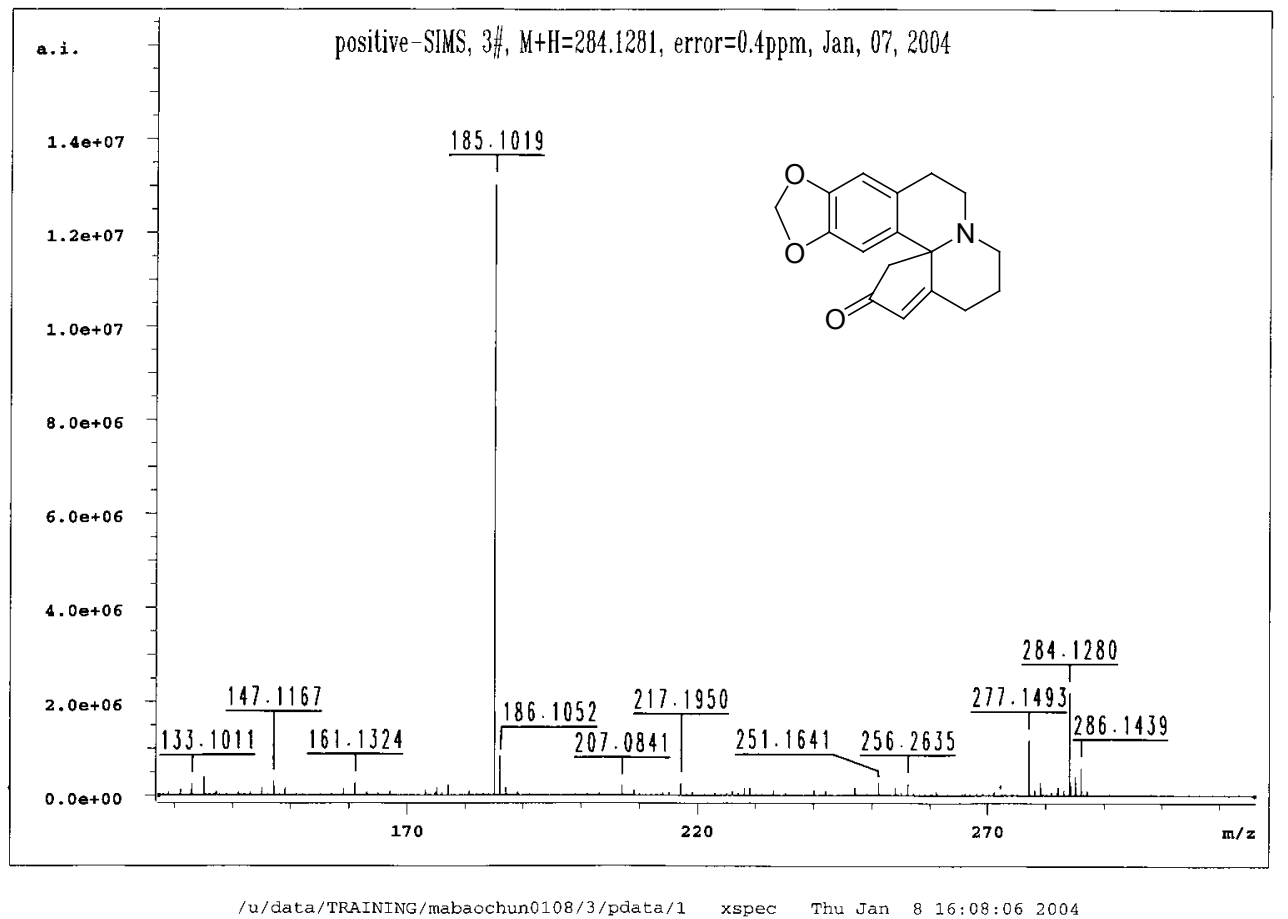


Table 1. x-ray crystallographic data of $\mathbf{1 4 a}$
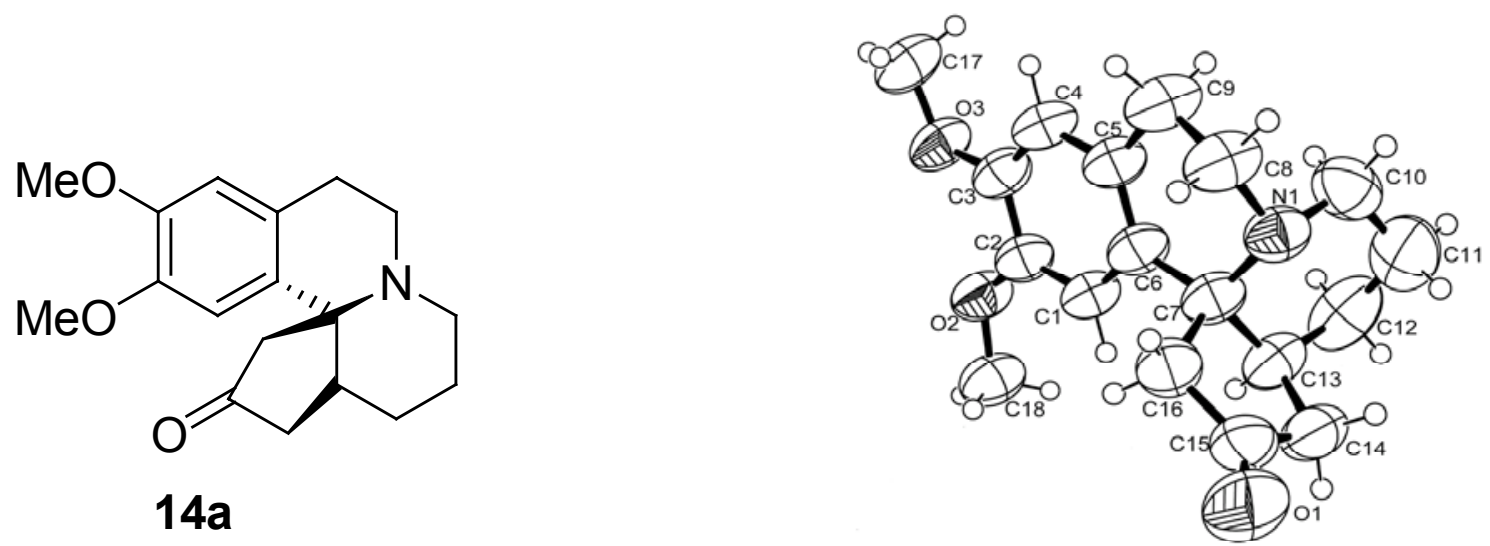

\begin{tabular}{lll}
\hline Color/shape & Colorless/block & \\
Crystal dimension $\left(\mathrm{mm}^{3}\right)$ & $0.4 \times 0.3 \times 0.3$ & \\
Chemical formula & $\mathrm{C}_{18} \mathrm{H}_{23} \mathrm{~N} \mathrm{O}_{3}$ & \\
Formula weight & 301.37 & \\
Temperature $(\mathrm{K})$ & $293(2)$ & \\
Crystal system & monoclinic & \\
Space group & $\mathrm{P} 21 / \mathrm{c}$ & $\alpha=90.00^{\circ}$ \\
Unit cell dimensions & $\mathrm{a}=10.958(2) \AA$ & \\
& $\mathrm{b}=16.203(3) \AA$ & $\AA$ \\
& $\mathrm{c}=9.101(2) \quad \AA$ & \\
& $1615.5(5)$ & \\
Volume $\left(\AA^{3}\right)$ & 4 & \\
$Z$ & 1.239 & \\
Density $\left(\mathrm{Mg} / \mathrm{m}^{3}\right)$ & 0.084 & \\
Absorption coefficient & Enraf-Nonius CAD4 & \\
Diffractometer & $\omega / 2 \theta$ & \\
Scan & $5.43-24.99$ & \\
$\theta$ range $\left({ }^{\circ}\right)$ & 2768 & \\
Reflections measured & $5775(0.2233)$ & \\
Independent reflections $\left(\mathrm{R}_{\text {int }}\right)$ & 1708 & \\
Observed reflections $(\mathrm{I}>2 \sigma \mathrm{I})$ & $2768 / 0 / 200$ & \\
Data/restraints/parameters & $6854(14)$ & \\
Extinction coefficient & 1.061 & \\
Goodness of fit on $\mathrm{F}^{2}$ & 0.0551 & \\
$\mathrm{R}_{1}(\mathrm{I}>2 \sigma(\mathrm{I}))$ & 0.1428 & \\
WR $_{2}($ all data $)$ & & \\
\hline
\end{tabular}

